San Jose State University

SJSU ScholarWorks

Master's Theses

Master's Theses and Graduate Research

Fall 2011

\title{
Effects of wearing a mouth guard and movement complexity on simple reaction time
}

Taijiro Hide

San Jose State University

Follow this and additional works at: https://scholarworks.sjsu.edu/etd_theses

\section{Recommended Citation}

Hide, Taijiro, "Effects of wearing a mouth guard and movement complexity on simple reaction time" (2011). Master's Theses. 4095.

DOI: https://doi.org/10.31979/etd.z6kq-wjzc

https://scholarworks.sjsu.edu/etd_theses/4095

This Thesis is brought to you for free and open access by the Master's Theses and Graduate Research at SJSU ScholarWorks. It has been accepted for inclusion in Master's Theses by an authorized administrator of SJSU ScholarWorks. For more information, please contact scholarworks@sjsu.edu. 


\title{
EFFECTS OF WEARING A MOUTH GUARD AND MOVEMENT COMPLEXITY ON SIMPLE REACTION TIME
}

\author{
A Thesis \\ Presented to \\ The Faculty of the Department of Kinesiology \\ San José State University \\ In Partial Fulfillment \\ of the Requirements for the Degree \\ Master of Arts \\ by \\ Taijiro Hide \\ December 2011
}


(C) 2011

Taijiro Hide

\section{ALL RIGHTS RESERVED}


The Designated Thesis Committee Approves the Thesis Titled

\section{EFFECTS OF WEARING A MOUTH GUARD AND MOVEMENT COMPLEXITY ON SIMPLE REACTION TIME}

by

Taijiro Hide

APPROVED FOR THE DEPARTMENT OF KINESIOLOGY

SAN JOSÉ STATE UNIVERSITY

December 2011

$\begin{array}{lll}\text { Dr. Emily H. Wughalter } & \text { Thesis Co-chair } & \text { Department of Kinesiology } \\ \text { Dr. James C. Kao } & \text { Thesis Co-chair } & \text { Department of Kinesiology } \\ \text { Dr. Kent J. Adams } & \text { Thesis Member } & \begin{array}{l}\text { Kinesiology Department } \\ \text { California State University } \\ \end{array} \\ & \begin{array}{l}\text { Monterey Bay } \\ \end{array}\end{array}$




\section{ABSTRACT \\ EFFECTS OF WEARING A MOUTH GUARD AND MOVEMENT COMPLEXITY \\ ON SIMPLE REACTION TIME}

by Taijiro Hide

The purpose of the study was to determine how use of a mouth guard and movement complexity affect reaction time of whole body movement. A design was developed to study whether wearing a mouth guard or not affects simple reaction time. Further, the study examined the hypothesis that movement complexity affects simple reaction time. The experiment consisted of three prescribed whole body movements of varying complexity. Participants in the experiment were 12 college aged males enrolled in a kinesiology major. They were free from injury and had some experience playing sports. Reaction time was determined using ground reaction force data measured by a force plate. Video data captured by a single video camera were digitized to verify the onset of movement. A two-way analysis of variance with repeated measures on both factors revealed no significant mouth guard effect. A significant movement complexity effect resulted in longer reaction times for a high complexity movement than for low and moderate complexity movements that revealed similar reaction times. A significant interaction effect resulted in shorter reaction times on the low and moderate complexity movements when wearing a self-adapted mouth guard than when not wearing a mouth guard. The current study examined the "memory drum" hypothesis by applying new technologies for understanding whole body movement. Further research will be required to replicate the results of the current study and to apply them to practice. 


\section{ACKNOWLEDGEMENTS}

I express my deepest gratitude to all who supported, encouraged, and advised me to make the completion of this thesis possible. My thesis co-chair, Dr. Emily Wughalter, provided continuous support, guidance, and encouragement throughout the thesis process. She contributed ideas and expanded my knowledge of motor learning, and my interest in the research process. Dr. James Kao served as co-chair of the thesis. He taught me to use the biomechanics equipment at the Timpany Center. He devoted his valuable time instructing me on how to use the equipment, and how to process and analyze the collected data. Dr. Kent Adams listened to me when I was struggling to find another committee member, and he assisted in the process while I was living in the Monterey Bay area.

Dr. Hideaki Iwamoto has been my mentor since I was a student at Fukuoka University in Japan. He introduced Dr. Tokuya Onitsuka to me. Dr. Tokuya Onitsuka, who is a lecturer at Fukuoka Dental College, supported me by sending abundant information and articles regarding dentistry.

I am indebted to all of those who devoted their time volunteering to participate in the data collection, particularly: Jeff Chan, Vrashank Dave, Jonathan Gragert, Mai-Huong Nguyen, Courtney Wong, Davidson Wong, and Jesse Yoshida. Also, I thank Hisashi Imura and Ken Howat for reviewing this thesis.

Last, but not least, I would like to thank my parents, Asao and Setsuko Hide, and my brother, Shinichiro Hide, for their constant support - mental, emotional, and financial. Without their help, I could not accomplish this thesis. 
Table of Contents

Page

List of Figures viii

List of Tables $\quad$ ix

Chapter 1 Introduction $\quad 1$

Statement of the Problem 5

Hypotheses $\quad 5$

$\begin{array}{ll}\text { Limitations } & 6\end{array}$

$\begin{array}{ll}\text { Delimitations } & 6\end{array}$

$\begin{array}{ll}\text { Definitions } & 7\end{array}$

$\begin{array}{ll}\text { Significance of the Study } & 7\end{array}$

Chapter 2 Review of the Literature $\quad 8$

Background on Use of Mouth Guards in Sport $\quad 8$

“Memory Drum" Theory 15

$\begin{array}{ll}\text { Summary } & 24\end{array}$

$\begin{array}{ll}\text { Chapter } 3 \text { Methods } & 27\end{array}$

$\begin{array}{ll}\text { Description of the Participants } & 27\end{array}$

Discussion of the Instrumentation Used for the Study 28

Presentation of the Movement Used for Data Collection 32

Organization of Procedures Used in the Experiment 36

Presentation of the Design $\quad 41$

Procedure for Statistical Analysis $\quad 42$ 
Discussion of the Dependent Variable 45

$\begin{array}{ll}\text { Summary } & 46\end{array}$

$\begin{array}{ll}\text { Chapter } 4 \text { Results } & 48\end{array}$

Presentation of the Results from the Analysis of Variance 48

Chapter 5 Discussion $\quad 52$

Discussion of the Results $\quad 52$

$\begin{array}{ll}\text { Recommendations for Future Study } & 57\end{array}$

$\begin{array}{ll}\text { Summary } & 59\end{array}$

$\begin{array}{ll}\text { References } & 62\end{array}$

Appendixes

Appendix A. Questionnaire for Health History 66

Appendix B. Permission for Redrawing of Howell Apparatus 69

$\begin{array}{ll}\text { Appendix C. Consent Form } & 71\end{array}$

Appendix D. Human Subjects-Institutional Review Board Approval 74

Appendix E. Audio Instruction for the Order of the Independent Variable 76 


\section{List of Figures}

Figure

Page

1. Type II mouth guard (Brain Pad, Inc., mode LP+ ${ }^{\mathrm{TM}}$ MOUTHGUARD) 11

2. Schematic for laboratory system 29

3. Schematic of experimental setting 30

4. Adaptation of Henry and Rogers' apparatus with distances 34

5. Adaptation of Henry and Rogers' apparatus with distances for movements 34

6. Schematic representing the distances between adjacent targets 35

7. The position of participant 38

8. Low complexity movement 39

9. Moderate complexity movement 40

10. High complexity movement 41

11. Comparison of the sampling rates for this study and Henry and Rogers' study $\begin{array}{ll}\text { (1960) } & 46\end{array}$

12. Significant interaction of mouth guard condition by movement complexity $\quad 50$ 


\section{List of Tables}

Table

Page

1. Research Design from Crossing the 2 (Mouth Guard Conditions) by 3 (Movement Complexity) with Repeated Measures on Both Factors

2. ANOVA Summary Table of the 2 (Mouth Guard Conditions) by 3 (Movement Complexity) Within Subject ANOVA

3. Means and Standard Deviations from the 2 (Mouth Guard) by 3 (Movement Complexity) Conditions 


\section{Chapter 1}

\section{Introduction}

A mouth guard covers teeth and absorbs internal and external forces affecting the mouth (Cornwell, Messer, \& Speed, 2003; Tran, Cooke, \& Newsome, 2001). Mouth guards protect athletes from orofacial (Lieger \& von Arx, 2006), dental (Hawn, Visser, \& Sexton, 2002; Labella, Smith, \& Sigurdsson, 2002; Perunski, Lang, Pohl, \& Filippi, 2005; Ranalli, 2002), and mandibular bone (Hawn et al., 2002) injuries as well as possible concussions (Cornwell et al., 2003; Knapik et al., 2007; Labella et al., 2002) from sports activities. The National Collegiate Athletic Association (NCAA) mandates athletes participating in sports such as American football, ice hockey, men's lacrosse, and women's field hockey wear mouth guards (Knapik et al., 2007).

Approximately 15 million people in the U.S. suffer from dental injuries every year (Kenyon \& Loos, 2005). Dental injuries requiring treatment account for $5 \%$ of all injuries (Flores et al., 2007). Of these traumatic dental injuries, one third is believed to occur during participation in physical activities or athletic contests (Nowjack-Raymer \& Gift, 1996; Lieger \& von Arx, 2006). Vastardis (2005) found that there are more than five-million avulsed teeth caused by physical activity and competitive athletics each year. The treatment of dental injuries is expensive relative to other injuries. It costs approximately $\$ 5,000$ to replace a tooth (Vastardis, 2005) and can be more than $\$ 15,000$ per tooth for lifetime treatment if the avulsed tooth is not replaced properly (Newsome, Tran, \& Cooke, 2001; Woodmansey, 1997). 
Numerous studies have reported about the population wearing a mouth guard and the rate of orofacial injuries on athletic performance (Badel, Jerolimov, \& Pandurić, 2007; Cornwell et al., 2003; Dillberović, Seifert, \& Jerolimov, 2004; Ferrari \& Medeiros, 2002; Hawn et al., 2002; Knapik et al., 2007; Kumamoto \& Maeda, 2005; Labella et al., 2002; Lieger \& von Arx, 2006; Newsome et al., 2001; Perunski et al., 2005; Santos \& Monte Alto, 2006; Soporowski, Tesini, \& Weiss, 1994; Woodmansey, 1997). Some have investigated the physical effects of wearing a mouth guard on simple reaction time (Bourdin et al., 2006; Burkett \& Bernstein, 1983), cardiovascular system indicators (Bourdin et al., 2006; Kececi, Cetin, Eroglu, \& Baydar, 2005; Thomas, Bowdoin, Brown, \& McCaw, 1998), strength measures (Bourdin et al., 2006; Burkett \& Bernstein, 1983), speaking ability (Eroglu, Diljin, \& Lutfi, 2006), and breathing rate (Bourdin et al., 2006; Eroglu et al., 2006).

Bourdin et al. (2006) tested the effect of wearing a mouth guard on simple reaction time, by pressing a button as a reaction to a stimulus light. They examined the simple reaction time for any difference between three mouth conditions which were wearing a self-adapted mouth guard, wearing a custom-made mouth guard, and not wearing a mouth guard. They found no significant simple reaction time differences between these three conditions. In the study of Bourdin et al., a simple small movement (pressing a button) was utilized to examine the simple reaction time and therefore it was still unknown whether the condition of wearing a mouth guard would affect simple reaction time of a more complex and dynamic movement. 
Henry and Rogers (1960) defined reaction time as the elapsed time between the appearance of a stimulus and an initial response to the stimulus. Reaction time is crucial for physical performance as it includes decision making and the organization of a response while an individual responds to any stimulus in the environment. Schmidt and Wrisberg (2000) suggested that reaction time is the measure of the speed of information processing.

In 1960, Henry and Rogers presented their seminal paper on the "memory drum" theory published in Research Quarterly (now Research Quarterly for Exercise and Sport), in which they described a relationship between the organization of the neuromotor program and reaction time delays. They postulated that complexity affects the systematic processing of movement beginning with conscious attention to organization. Once a task is mastered the process could be stored as a neuromotor program and it could be performed more autonomously. Moreover, Henry and Rogers hypothesized that as movement complexity increases more information is required for the response organization, and therefore participants need more time to retrieve information from the stored program and relay the information to proper motor neurons and muscles to accomplish the tasks. They hypothesized that a longer reaction time would be required to perform more complex movement than more simple movement using a simple reaction paradigm.

In their experiment, Henry and Rogers (1960) introduced three movements of varying complexity. Movement A consisted of a simple and single movement, which was to lift a finger from a reaction button. Movement B was composed of three movements, 
which included Movement A followed by reaching and grasping a hanging tennis ball. Movement $\mathrm{C}$ was the most complex movement, consisting of Movement $\mathrm{A}$, striking a hanging tennis ball, touching a dummy button, and then striking a second hanging tennis ball. Through their experiment, Henry and Rogers found that Movement B required 20\% longer simple reaction time than Movement A, and Movement $\mathrm{C}$ required 7\% longer simple reaction time than Movement B; therefore, they confirmed the memory drum hypothesis that longer simple reaction times would be required to perform more complex movements than more simple movements.

Since Henry and Rogers (1960) introduced the "memory drum" theory, many researchers have replicated and extended the original notions (Anson, 1982; Bjørklund, 1992; Christina, Fischman, Vercruyssen, \& Anson, 1982; Klapp, Wyatt, \& Lingo, 1974; Phillips \& Glencross, 1985). In all of these studies the movements tested were limited to the upper extremities (finger, elbow, or shoulder) and small motor movements.

The purpose of this study was to investigate the hypothesis advanced by Henry and Rogers (1960) in the "memory drum" theory, i.e., that increases in movement complexity would result in changes in simple reaction time. These changes are reflective of the motor programming required as movement becomes more complicated. In this experiment, the effects of movement complexity (with three varying complexities) were manipulated across two mouth guard conditions (when participants were either wearing a self-adapted mouth guard or not wearing a mouth guard) to study their impact on simple reaction time. Simple reaction time was determined using vertical ground reaction force data measured by a force plate. Video data captured by a single video camera were 
digitized to verify the onset of movement. This study contributes to an interdisciplinary nexus of principles from biomechanics and motor learning to study Henry and Rogers' hypothesis that allowed for a whole body movement task to be used to measure simple reaction time. Specifically the purpose of the study was to determine how use of a mouth guard and movement complexity affect simple reaction time of a whole body movement task.

\section{Statement of the Problem}

The purpose of this study was to investigate:

1. How does mouth guard condition (wearing a self-adapted mouth guard and not wearing a mouth guard) affect simple reaction time?

2. How does movement complexity (simple, moderate, and complex) affect simple reaction time?

3. How do mouth guard condition and movement complexity affect simple reaction time?

\section{Hypotheses}

The following null hypotheses were designed for the purpose of this study:

1. Mouth guard condition will not affect simple reaction time.

2. Movement complexity will not affect simple reaction time.

3. Mouth guard condition and movement complexity will not affect simple reaction time. 


\section{Limitations}

The study was limited by the following factors:

1. The self-adapted mouth guard was molded by each participant following written instructions. The accuracy for making a proper mouth guard depended on how accurately they followed the instructions.

2. The participants in this study were university male students. The results from this study should only be generalized to males of a similar age range.

3. This study was designed for testing simple reaction time of complex and dynamic movements of the lower extremity in completely controlled laboratory settings. Therefore, the results from this study may not generalize to the real-sports situations such as the reaction of a defensive player in basketball or of an offensive line player in football.

\section{Delimitations}

The study was delimited to:

1. Participants who had no experience wearing a mouth guard.

2. Participants who had experience engaging in organized scholastic or intercollegiate athletics for at least one year.

3. Participants who had no acute or subacute injuries to the lower extremities (toes, arch, heel, ankle, Achilles tendon, cuff muscles, shin, knee, quadriceps and hamstring muscles) or lower back. They reported no neuromuscular deficits, nor did they have any visual or auditory dysfunction as diagnosed by a doctor. 


\section{Definitions}

Reaction time. Reaction time is measured as the elapsed time between the appearance of a stimulus and the initial movement that responds to the stimulus (Henry \& Rogers, 1960).

Simple reaction time. Simple reaction time involves the appearance of a single stimulus with a single response which can be known before the stimulus appears (Henry \& Rogers, 1960). For the purposes of this study simple reaction time was measured via the onset of movement digitized from ground reaction force data measured by a force plate and video data captured by single video camera.

Self-adapted mouth guard. Self-adapted mouth guards are also called Type II or boil and bite mouth guards, which are shaped by a user through a process of immersion in boiling water and then pressure from lips, tongue, and teeth to shape it.

\section{Significance of the Study}

This study was designed to investigate how mouth guard condition (wearing a self-adapted mouth guard and not wearing a mouth guard) and movement complexity (simple, moderate, and complex) affect simple reaction time. Significant mouth guard

effects may result in better information for athletes about whether wearing a mouth guard has an influence on their performance. The results from testing simple reaction time on different movement complexities will also contribute toward revealing whether the notions from the "memory drum" theory (Henry \& Rogers, 1960) apply to examining lower extremity and large body movements of varying complexities. 


\section{Chapter 2}

\section{Review of the Literature}

The purpose of this study was to investigate the hypothesis advanced by Henry and Rogers (1960) in the "memory drum" theory, i.e., that increases in movement complexity result in changes in simple reaction time. They proposed that these changes are reflective of the changes in motor programming required as movement becomes more complicated. In this experiment, the effects of movement complexity (with three varying complexities) were manipulated across two mouth guard conditions (when participants were either wearing a self-adapted mouth guard or not wearing a mouth guard) to study their impact on simple reaction time. Simple reaction time was determined using vertical ground reaction force data measured by a force plate. Video data captured by a single video camera were digitized to verify the onset of movement. This chapter presents a review of the following topics: a background on use of mouth guards in sport, a "memory drum" theory, and a summary.

\section{Background on Use of Mouth Guards in Sport}

Mouth protection was first used in sports events by boxers (Knapik et al., 2007; Hawn et al., 2002). Boxers protected their mouth, teeth, and jaw by placing cotton, tape, sponge, or pieces of wood in their mouth (Knapik et al. 2007). Today, new designs for mouth guards use different materials and shapes than the original ones. Phillip Krause, whose father was a dentist, used resin as a mouth guard and introduced a reusable mouth guard for the first time in 1910 (Knapik et al., 2007). Since then, the materials and 
shapes of the reusable mouth guard have changed further to improve the absorption of shock and its durability.

Wearing a mouth guard was popularized not only by boxing but also by other sports in the United States. During the 1940s and 1950s, 23-54\% of all injuries were dental injuries among American football players, which included high-school and college athletes (Knapik et al., 2007). Individual high-schools and colleges have enforced precautionary measures by enforcing the wearing a mouth guard while playing American football because of the high rate of dental injuries (Knapik et al., 2007). Since each individual high-school and college had enforced wearing a mouth guard while playing American football, the National Alliance Football Rules Committee and the National Collegiate Athletic Association (NCAA) mandated in 1962 and 1973 wearing a mouth guard for American Football players during competition (Knapik et al., 2007).

The purpose of wearing a mouth guard is to absorb and reduce a force and an impact from outside and inside a mouth (Cornwell et al., 2003; Tran et al., 2001). Therefore, a mouth guard can prevent and reduce orofacial (Lieger \& von Arx, 2006), dental (Hawn et al., 2002; Labella et al., 2002; Perunski et al., 2005; Ranalli, 2002) and mandibular bone (Hawn et al., 2002) injuries during physical activities and sports events (Lieger \& von Arx, 2006). In addition to the prevention of orofacial, dental and mandibular bone injuries, a mouth guard can potentially reduce the rate of concussion (Cornwell et al., 2003; Knapik et al., 2007; Labella et al., 2002). Mouth guards are available for athletes in three types including Type I, II, and III (Newsome et al., 2001). 
Type I, also known as a stock mouth guard, is inexpensive, retails for less than $\$ 5$, and does not require molding to the shape of teeth. To hold the mouth guard inside the mouth, the teeth must be clenched, and therefore it affects speaking and breathing while it is worn (Woodmansey, 1997). Type I mouth guards can be purchased at a sporting-goods department in a commercial shopping center. Type I mouth guard is no longer used by athletic populations because it does not fit closely enough with the user's teeth (Newsome et al., 2001). The other types of mouth guard (Type II and III) are better known and are more widely used by athletes (Hawn et al., 2002).

Type II, also known as a boil and bite or a self-adapted mouth guard, has a similar shape as the Type I mouth guard but requires shaping by users. To shape it for the teeth, a user immerses the mouth guard into hot water for a few seconds and then places it on the upper teeth with pressure from fingers, tongue, and teeth (see Figure 1). The Type II mouth guard can also be purchased at a sporting-goods department in a commercial shopping center. It is relatively inexpensive and costs less than $\$ 10$. Consequently, the Type II mouth guard accounts for 90-95\% of the market share of all mouth guard users (Woodmansey, 1997). Even though the Type II mouth guard is reasonably priced and easily available, it also requires clenching to hold it inside a mouth in the same way as the Type I. Therefore, it is less functional in comparison with a Type III mouth guard. 




Figure 1. Type II mouth guard (Brain Pad, Inc., mode LP+ ${ }^{\text {TM }}$ MOUTHGUARD) as a function of upper and lower teeth (top row, left and right columns respectively), and before and after participant formation (bottom row, left and right columns respectively).

The Type III is known as a custom-made mouth guard. First, a dentist measures the structure of teeth and forms the replica of teeth with plaster. It is then molded by a vacuum-forming technique, a pressure-lamination technique, or the combination of these two techniques (Ranalli, 2002). Thus, the custom-made mouth guard is relatively more expensive than $\$ 50$ but less than $\$ 200$ (Woodmansey, 1997). Even though the custommade mouth guard is expensive, it is believed to be the most durable and satisfactory mouth guard in comparison with the other types (Ranalli, 2002; Newsome et al., 2001).

Several materials are used when making mouth guards and the majority of these are polyvinylacetate-polyethylene, polyvinylchloride, latex rubber, acrylic resin, and poly-urethane. Polyvinylacetate-polyethelene copolymer known as ethylene vinyl acetate (EVA) is most widely used as the material for making mouth guards (Going, Loehman, \& Chan, 1974; Tran et al., 2001). 
Numerous studies exist examining the effects of wearing a mouth guard on orofacial, dental, and mandibular bone injuries and concussions among athletic populations (Badel et al., 2007; Cornwell et al., 2003; Dillberović et al., 2004; Ferrari \& Medeiros, 2002; Hawn et al., 2002; Knapik et al., 2007; Kumamoto \& Maeda, 2005; Labella et al., 2002; Lieger \& von Arx, 2006; Newsome et al., 2001; Perunski et al., 2005; Santos \& Monte Alto, 2006; Soporowski et al., 1994; Woodmansey, 1997). Some studies further investigated the physical effects of wearing a mouth guard on simple reaction time (Bourding et al., 2006; Burkett \& Bernstein, 1983), cardiovascular system indicators (Bourdin et al., 2006; Kecei et al., 2005; Thomas et al., 1998), strength measures (Bourdin et al., 2006; Burkett \& Bernstein, 1983), speaking ability (Eroglu et al., 2006), and breathing rate (Bourdin et al., 2006; Eroglu et al., 2006).

Bourdin et al. (2006) investigated the effects of wearing a mouth guard on simple reaction time, oral airflow dynamics, and maximal oxygen consumption. They tested 19 athletes from the sports of handball $(n=2)$, ice hockey $(n=1)$, and rugby $(n=16)$. These 15 athletes performed further testing of incremental exercise until exhaustion. Each participant performed the tests under three different conditions: not wearing a mouth guard, wearing a self-adapted mouth guard, and wearing a custom-made mouth guard. In their conclusion, Bourdin et al. stated that the self-adapted and the custom-made mouth guards did not significantly affect simple reaction time, oral airflow dynamics, forcevelocity measurements, or the test of incremental exercise until exhaustion. Therefore, Bourdin et al. concluded that the mouth guards did not affect team sport performance. 
Taekwondo is a Korean martial art that requires players to strike, stamp on, and kick opponents during a match. In Taekwondo, there are numerous and severe orofacial injuries; therefore, a mouth guard is crucial for preventing or reducing these injuries. Kecei, Cetin, Eroglu, and Baydar (2005) examined if a custom-made mouth guard would affect athletic aerobic performance. The researchers tested ventilatory gas exchange variables (oxygen consumption, carbon dioxide production, minute ventilation, and respiratory exchange ratio) and heart rate on a $20 \mathrm{~m}$ shuttle run for 22 young elite Taekwondo athletes, whose age range was 14-17 years. Each participant performed the $20 \mathrm{~m}$ shuttle run under two different conditions, which were wearing a mouth guard and not wearing a mouth guard across both conditions. Keçei et al. concluded no significant differences existed in the ventilatory gas exchange variables between the two conditions; therefore, the custom-made mouth guard had no negative effect on aerobic performance. Most sports, especially games played with balls, require some type of anaerobic activity or motion. Thomas, Bowdoin, Brown, and McCaw (1998) revealed a relationship between anaerobic performance and wearing a self-adapted mouth guard, even though the main focus of their study was to assess the effect of a nasal strip on anaerobic performance. Thomas et al. tested 15 participants whose ages ranged from 1926 years on peak power output at each 5-second mark for a 30-second cycling on an ergometer. They also tested anaerobic capacity, which was an average workload for a 30second cycling on the ergometer. In this study, participants pedaled on the ergometer for 30 seconds under six different conditions: not wearing a mouth guard without a strip; wearing a mouth guard without a strip; not wearing a mouth guard with a placebo strip; 
wearing a mouth guard with a placebo strip; not wearing a mouth guard with a nasal strip; and wearing a mouth guard with a nasal strip. In their conclusion, Thomas et al. reported no significant differences existed in either the peak anaerobic power or the anaerobic capacity between wearing a mouth guard and not wearing a mouth guard. Therefore, they concluded that the mouth guard condition did not affect anaerobic performance.

Impact sports, such as American football, wrestling, and rugby, demand a high level of muscular strength and power. To some degree, punching, pushing, tackling, and grappling opponents are involved in these sports. American football players, who are mandated to wear a mouth guard by the NCAA (Knapik et al., 2007), have significant concern for how the condition of wearing a mouth guard will affect their muscular strength and power. Burkett and Bernstein (1983) investigated the effect of a Mandibular Orthopedic Repositioning Appliance (MORA) mouth guard on muscular strength, muscular endurance, reaction time, and movement time. Participants were 27 volunteers placed into one of two groups. The MORA mouth guard group consisted of 15 participants, while12 participants wore a placebo MORA mouth guard. While wearing an assigned mouth guard, all participants performed reaction movement, bilateral maximal grip strength and endurance, bilateral maximal static and dynamic quadriceps strength, and bilateral maximal static and dynamic hamstrings strength exercises. Burkett and Bernstein concluded that there were no significant differences in reaction time, movement time, muscular strength, or muscular endurance between the participants wearing the MORA mouth guard and the placebo MORA mouth guard. 


\section{“Memory Drum" Theory}

Henry and Rogers (1960) defined reaction time as the elapsed time between an appearance of a stimulus and an initial movement in response to the stimulus, and therefore reaction time is a critical aspect of sport performance. For many years, researchers have studied and examined the factors that affect the duration of reaction time. In 1960, Henry and Rogers presented the "memory drum" theory. They described a relationship between a neuromotor program and reaction time. Henry and Rogers postulated that a movement is acquired by conscious step-by-step mannered practice, and once the task is mastered and stored in the neuromotor program, it could be executed autonomously. Complex tasks contain more information than simple tasks, and therefore complex tasks require more time to retrieve information from a stored program and to send the information to proper motor neurons and muscles. Thus, Henry and Rogers hypothesized that a longer reaction time would be required for performance of complex movements than for performance of simple movements in simple reaction time paradigms.

Henry and Rogers (1960) introduced three movements to test their hypothesis. Movement A consisted of a simple and single movement, which was to lift a finger from a reaction button. Movement B was composed of three movements: Movement A followed by reaching and grasping a hanging tennis ball. Movement $\mathrm{C}$ was the most complex movement, which consisted of Movement A followed by striking a hanging tennis ball, touching a dummy button, and striking a second hanging tennis ball. Through their experiment, Henry and Rogers found that Movement B required 20\% longer simple 
reaction time compared with Movement $\mathrm{A}$ and Movement $\mathrm{C}$ required 7\% longer simple reaction time compared with Movement $\mathrm{B}$, which confirmed their hypothesis that a longer reaction time was required to perform a complex movement. Moreover, they found that female college students tended to have a longer simple reaction time than male college students. In addition, 8 year-old boys had a longer simple reaction time than 12 year-old boys. Henry and Rogers recommended future research examine how simple reaction time would be affected by the degree of complexity, accuracy and precision of a movement, and by the degree of feedback (Henry \& Rogers, 1960).

Klapp, Wyatt, and Lingo (1974) challenged Henry and Rogers' "memory drum" notion. They questioned why Henry and Rogers (1960) chose to examine the relationship between a neuromotor program and reaction time using a simple reaction paradigm, in which a participant performs a movement in response to a single stimulus, and not a choice-reaction paradigm, in which a participant performs a specific movement from several movements in response to a specific stimulus out of several stimuli (Klapp et al., 1974).

According to Klapp et al. (1974), the process of retrieving proper information from a stored program and sending the information to proper motor neurons and muscles for performing a task might be initiated before an appearance of the stimulus when a person performs the simple reaction paradigm. They argued that a simple reaction paradigm was not appropriate to examine the relationship between a neuromotor program and the reaction time. Conversely, a participant cannot retrieve or process the information before the appearance of a stimulus because of the unknown direction of the 
response in a choice-reaction paradigm. Klapp et al. argued that the simple reaction paradigm was susceptible to practice, which meant that the information processing required would be omitted. Therefore, programming or the "memory drum" theory would not be applicable to the simple reaction paradigm but rather for a choice-reaction paradigm.

Since the argument was raised by Klapp et al. (1974), the "memory drum" theory debate exists whether to use simple reaction paradigm or choice-reaction paradigm and for examining the relationship between a neuromotor program and the reaction time (Phillips \& Glencross, 1985). In 1980, Henry counter-argued in a response to Klapp et al. using the choice-reaction paradigm and the practice effect to examine the relationship between a neuromotor program and reaction time. Henry explained that the choicereaction paradigm would require a participant to identify a stimulus and a proper response, in other words, contains both movement selection and program selection. Therefore, the choice-reaction paradigm was inappropriate for testing the relationship between the neuromotor program and reaction time.

In response to Henry's argument, Klapp (1980) restated his point of view by differentiating the results of his study with his colleagues (Klapp et al., 1974) from the results of Henry and Rogers's study (1960). Henry mentioned that the Klapp et al. (1974) introduced a small-scale vocal and finger movement for testing simple reaction time as well as choice-reaction time. On the other hand, Henry and Rogers introduced a small movement (lifting the index finger) as well as a large movement (extension and flexion of shoulder and elbow, with touching, striking, and grasping a ball) for testing simple 
reaction time. The two different movements led to different outcomes. Klapp argued that the large movement, which was used in the Henry and Rogers' study, did not constitute a complex movement. Therefore, Henry and Rogers should have introduced a complex movement in their experiment to examine the relationship between a neuromotor program and the reaction time. Even though Klapp pointed out that the movements from Henry and Rogers' study cannot be called a complex movement, Klapp did not define the meaning of a complex movement. Secondly, Klapp et al. used a simple and small movement in their study. Therefore, the design of the Henry and Rogers' study seemed to be more reliable and appropriate to describe the relationship between a neruomotor program and the reaction time than the study of Klapp et al. because the movements in the Henry and Rogers' study required more motions, longer durations, and greater accuracy and precision of the movements than their study.

Even though the original "memory drum" theory has been debated over 5 decades, many researchers have supported, replicated, and even extended the Henry and Rogers' study (1960). Their ideas are central to the notion of motor control programming (Klapp, 1980). In extending the original theory, researchers investigated the effects of an involved motor unit (Anson, 1982), complexity of movement (Christina et al., 1982), movement time (Phillips \& Glencross, 1985), and foreperiod interval (Bjørklund, 1992).

Anson (1982) focused on the different outcomes derived from peripheral factors used by the Henry and Rogers' study (1960) and the study of Klapp et al. (1974). According to Anson, the peripheral factors include anatomical and physiological features. The anatomical features are the number and size of body part exerted to perform a 
movement. Physiological features consist of the organization of musculature, fiber type, and innervations ratio. In addition to the peripheral factors, the target size and the distance of movements were also examined with respect to how these factors influenced simple reaction time. For investigating the effect of peripheral factors on simple reaction time, Anson introduced three reaction buttons under an index finger, wrist, and elbow to record the simple reaction times from these body parts and asked participants to release a button under an index finger (finger extension), index finger and wrist (elbow flexion), or index finger, wrist, and elbow (shoulder flexion) in response to a stimulus. Anson also introduced electromyography (EMG) to measure premotor time, which represents a central programming on an extensor indicis, an anterior deltoid, biceps and pectoralis major muscles. For testing the effect of target size, Anson used three different-target sizes which were $25.4 \mathrm{~cm}^{2}, 6.35 \mathrm{~cm}^{2}$, and $0.79 \mathrm{~cm}^{2}$ and asked participants to hit the target in response to a stimulus on the shoulder-flexion task. To investigate the effect of distance of movements, the results from the simple reaction time of shoulder flexion with and without a $25.4 \mathrm{~cm}^{2}$ target were compared. In this study, Anson found that increasing an involved anatomical unit (shoulder flexion compared with finger flexion) and the decrease of target size $\left(0.79 \mathrm{~cm}^{2}\right.$ compared with $\left.25.4 \mathrm{~cm}^{2}\right)$ increased simple reaction time due to increased electromechanical delay and increased accuracy of movement, but the distance of movement did not influence simple reaction time.

Since the Anson's study (1982) focused on Movement A and B from the Henry and Rogers' study (1960), Christina, Fischman, Vercruyssen, and Anson (1982) investigated how different factors of Henry and Rogers' Movement B and C affected 
simple reaction time. To compare each factor from Movement B and C, Christina et al. divided Movement $\mathrm{C}$ into two different responses: $\mathrm{C} 1$ and $\mathrm{C} 2$ responses, and examined simple reaction time for an index finger in Movement $\mathrm{B}$ and $\mathrm{C}$ and $\mathrm{C} 1$ and $\mathrm{C} 2$ responses. $\mathrm{C} 1$ response consisted of releasing an index finger from a reaction button and touching a tennis ball; therefore, it was thought as similar to Movement B. C2 response consisted of $\mathrm{C} 1$ response followed by touching a second button. Through the experiment, Christina et al. found that simple reaction time for Movement $\mathrm{C}$ was longer than Movement $\mathrm{B}$ and simple reaction time for $\mathrm{C} 2$ response was longer than Movement $\mathrm{B}$ and $\mathrm{C} 1$ response. Consequently, these results could support the "memory drum" theory in which Henry and Rogers predicted a complicated task requires longer simple reaction time than a simple task. Christina et al. also had unexpected results that simple reaction time for Movement B was shorter than $\mathrm{C} 1$ response, but total movement time of $\mathrm{C} 1$ response was $40 \%$ shorter than Movement B. The researchers assumed that Movement B and C1 response contained similar features. Therefore, simple reaction times and movement times of these movements would be similar.

The unexpected results from the study of Christina et al. (1982) led the researchers to reassess these two movements. They introduced an additional reaction button under the elbow to examine simple reaction times as well as movement times for the index finger and the elbow in Movement $\mathrm{B}$ and $\mathrm{C}$ and $\mathrm{C} 1$ and $\mathrm{C} 2$ responses. The results of the reassessment showed that simple reaction times of the elbow were shorter than the finger at $\mathrm{C} 1$ response, $\mathrm{C} 2$ response, and Movement $\mathrm{C}$, and simple reaction time of the elbow at $\mathrm{C} 1$ response was shorter than both simple reaction times from the finger 
and the elbow at Movement B. Moreover, Christina et al. found that the movement time of the elbow at $\mathrm{C} 1$ response was $27 \%$ shorter than the movement time of the finger at Movement $\mathrm{B}$, and the movement time of the elbow at $\mathrm{C} 1$ response was significantly shorter than the movement times of the elbow at $\mathrm{C} 2$ response and Movement $\mathrm{C}$. Even though the results indicated that the simple reaction time of the elbow at $\mathrm{C} 1$ response was shorter than the finger at Movement B, it cannot be said that the Henry and Rogers' study (1960) failed to support the "memory drum" theory because Christina et al. also admitted the falsehood of their assumption that Movement B and C1 response were composed of the same motion.

The two movements required significantly different motions. One was to grasp a tennis ball, and the other was to strike a tennis ball. Therefore, to grasp the tennis ball at Movement B was more complicated than to strike the tennis ball at $\mathrm{C} 1$ response (Christina et al., 1982). Christina et al. (1982) failed to support their assumptions, but they discovered a very important point that the shorter simple reaction times were found in different body parts for different responses. Moreover, this finding also confirmed that the increase in simple reaction time in the results from an increase in complexity of the movement (158 $\mathrm{ms}$ for the elbow in $\mathrm{C} 1$ response, $168 \mathrm{~ms}$ for the index finger in Movement B, $178 \mathrm{~ms}$ for the elbow in C2 response, and $182 \mathrm{~ms}$ for the elbow in Movement C). In their conclusion, Christina et al. suggested that simple reaction time was affected by four characteristics of the task: duration of movement, accuracy of movement, directional change in movement, and distance of movement. 
Even though Christina et al. (1982) found that movement time on a relatively simple task was shorter than movement time on relatively complex tasks, these results could not provide a strong relationship between reaction time and movement time because the movement time of $\mathrm{C} 1$ component of Movement $\mathrm{C}$ was shorter than the movement time of $\mathrm{C} 1$ component of $\mathrm{C} 2$ response. Thus, Phillips and Glencross (1985) investigated the relationship between reaction time and movement time as well as movement accuracy. Phillips and Glencross used a simple reaction paradigm on a simple aiming movement, which was to move a stylus from a starting point to within a target circle in response to a sound stimulus. The researchers examined three conditions: controlled reaction time only, controlled movement time only, and controlled both reaction time and movement time. Phillips and Glencross examined each participant's ability to control reaction time (either $150-200 \mathrm{~ms}$ or $200-250 \mathrm{~ms}$ ), and then examined ability to control movement time (either $150-200 \mathrm{~ms}$ or $200-250 \mathrm{~ms}$ ). Each participant received the reaction time feedback after each trial of the controlled reaction time condition and the movement time feedback after each trial of the controlled movement time condition if the participants could not maintain the speed of reaction time or movement time. The researchers also instructed each participant to control both reaction time and movement time, and either the feedback of reaction time or movement time was given to participants after each trial when the participants could not control assigned reaction time and movement time. In their conclusion, Phillips and Glencross found that the controlled reaction time was not affected by controlled movement time, and vice versa. Phillips and Glencross also found that attempting shorter reaction time 
complicated the accuracy of a movement. Phillips and Glencross questioned the argument of Klapp et al. (1974) in which the simple reaction paradigm was not appropriate to examine the relationship between a neuromotor program and the reaction time because a task might be initiated or preprogrammed before an appearance of the stimulus. In the experiments of Phillips and Glencross, the participants could separate or control reaction time or movement time separately, but they could not control the accuracy of a movement when they attempted shorter reaction time on the movement. The Phillips and Glencross' findings suggest that the completion of a preprogramming movement before an appearance of the stimulus would not occur. Therefore, the work of Phillips and Glencross supports the experimental setting of Henry and Rogers' study (1960), which used the simple reaction paradigm to examine the relationship between a neuromotor program and the reaction time.

A foreperiod, which is the time between an appearance of a warning sign and a stimulus, is also one of the important factors used to describe the mechanism of reaction time. Bjørklund (1992) investigated a relationship between the foreperiod and simple reaction time. Bjørklund's task required participants to release an index finger from a first button, to press a second button, and then to press the first button again by using the same finger. A visual warning sign was given, followed by the appearance of a visual stimulus after one of five foreperiod intervals: 500, 889, 1581, 2012, and $5000 \mathrm{~ms}$. Through the study, Bjørklund found that the shortest reaction time was measured at the $1581 \mathrm{~ms}$ foreperiod setting, and the reaction time gradually and significantly increased when the foreperiod interval was set shorter or longer than the $1581 \mathrm{~ms}$ period. 
"Memory drum" theory was presented by Henry and Rogers (1960) 51 years ago, but this old theory is still the central notion of the motor control programming (Klapp, 1980). The "memory drum" hypothesis is supported and similar findings are replicated by many researchers. Moreover, some of these researchers modified the experimental setting of the Henry and Rogers' study to examine whether the theory could apply to different experimental settings (Anson, 1982; Bjørklund, 1992; Christina et al., 1982; Klapp et al., 1974; Phillips \& Glencross, 1985). As Henry and Rogers suggested for future research, the effects of many factors (including: the degree of complexity, accuracy and precision of movement, and degree of feedback) on simple reaction time, have been examined, and those factors contribute to the understanding of the mechanism of reaction time as well as "memory drum" theory.

\section{Summary}

Since 1910, the materials and shapes of reusable mouth guards have changed (Knapik, et al., 2007) to improve the shock absorption and durability. Type II, also known as a boil and bite or a self-adapted mouth guard and Type III, also called a custom-made mouth guard, are currently two types of mouth guards available and widely used among athletic populations (Hawn et al., 2002). These mouth guards have both advantages and disadvantages. The self-adapted mouth guard is relatively inexpensive and can be purchased at a sporting-goods department in a commercial shopping center. However, it does not fit closely with the teeth compared with the custom-made mouth guard and requires teeth clenching to hold it inside the mouth. Therefore, it limits speaking and breathing while it is worn. By contrast, the custom-made mouth guard is 
made by a dentist who measures the tooth structure and forms a replica. Therefore, it is well fitted to individual teeth and presents fewer limitations to speaking and breathing. However, it is the most expensive mouth guard, and the cost reduces its popularity.

Many researchers have reported the effects of wearing a mouth guard on orofacial, dental, and mandibular bone injuries and concussions among athletic populations (Badel et al., 2007; Cornwell et al., 2003; Dillberović et al., 2004; Ferrari \& Medeiros, 2002; Hawn et al., 2002; Knapik et al., 2007; Kumamoto \& Maeda, 2005; Labella et al., 2002; Lieger \& von Arx, 2006; Newsome et al., 2001; Perunski et al., 2005; Santos \& Monte Alto, 2006; Soporowski et al., 1994; Woodmansey, 1997). Some further investigated how wearing a mouth guard affected simple reaction time, oral airflow dynamics, maximal oxygen consumption (Bourdin et al., 2006), aerobic ventilator gas exchanges (Keçei et al., 2005), anaerobic peak power output, anaerobic capacity (Thomas et al., 1998), strength, reaction time, and movement time (Burkett \& Bernstein, 1983).

Significant differences between the conditions of wearing a mouth guard and not wearing a mouth guard on these variables were not found.

Reaction time, which is defined as an elapsed time between the appearance of a stimulus and an initial response to the stimulus (Henry \& Rogers, 1960), is crucial for physical performance because it is deeply rooted in decision making and how an individual chooses an optimal movement for a given stimulus. Researchers believe that reaction time displays the speed of an information process (Schmidt \& Wrisberg, 2000). Since Henry and Rogers (1960) presented the "memory drum" theory, stating that a longer reaction time would be required to accomplish a complex movement compared 
with a simple movement in a simple reaction paradigm, many researchers have studied and replicated the experiment of Henry and Rogers. Moreover some of these researchers modified the experimental setting from the Henry and Rogers' study and found that increasing an involved anatomical unit and decreasing a target size slow simple reaction time due to increased electromechanical delay (Anson, 1982), increasing the complexity of a movement slows simple reaction time (Christina et al, 1982), attempting shorter reaction time disturbs accuracy (Phillips \& Glencross, 1985), and a $1581 \mathrm{~ms}$ foreperiod generates the shortest simple reaction time (Bjørklund, 1992). 


\section{Chapter 3}

\section{Methods}

This study investigated the hypothesis advanced by Henry and Rogers (1960) in the "memory drum" theory, i.e., that increases in movement complexity result in changes in simple reaction time. The purpose was to determine the effects of movement complexity (with three varying complexities) and mouth guard conditions (when participants were either wearing a self-adapted mouth guard or not wearing a mouth guard) on simple reaction time. This chapter presents the following topics: a description of the participants, a discussion of the instrumentation used for the study, a presentation of the movements used for data collection, an organization of procedures used in the experiment, a presentation of the design, the procedures for statistical analysis, the specific data selected for analysis, a discussion of the dependent variable, and a summary.

\section{Description of the Participants}

Participants were 12 male student volunteers recruited from Kinesiology major classes and a Department of Kinesiology listserv at a large, metropolitan institution. The criteria for the participants included no experience of wearing a mouth guard. They all had some experience participating in organized scholastic or intercollegiate athletics for at least one year. Prior to the experiment, participants answered the health history questionnaire (Appendix A), and participants who had acute or subacute injuries based on a classification for care of acute injuries (Knight, 2008) to lower extremities (toes, arch, heel, ankle, Achilles tendon, gastrocnemius muscles, shin, knee, quadriceps and 
hamstring muscles), lower back, neuromuscular deficits, and visual and auditory dysfunction were excluded from this study.

\section{Discussion of the Instrumentation Used for the Study}

Electromyography (EMG). DataLOG (Biometrics Ltd., model W4X8) was used to collect EMG data from surface electrodes (Biometrics Ltd., model SX230 EMG Sensor) to measure muscle activation levels during the reaction time phase of movements with degrees of complexity. The surface electrodes, which contain two electrodes (10 $\mathrm{mm}$ in diameter and $20 \mathrm{~mm}$ in distance between each electrode), were placed on both masseter muscles above the angle of the mandibular bone for measuring the activity of mouth. Surface electrodes were also placed over the distal end of vastus medialis muscle, and over the muscle belly of the gastrocnemius on both legs. The EMG data collected by the DataLOG device were wirelessly transferred to the Biometrics Analysis Software (Biometrics Ltd., model v7.5), which stores and displays analog and digital data on the screen, for analyzing fractionated reaction time.

Video recorder. Two video cameras (Canon, model ZR65MC) were set at approximately $500 \mathrm{~cm}$ posteriorly, $250 \mathrm{~cm}$ laterally from the force plates, and $250 \mathrm{~cm}$ from the floor in order to capture the movements of each trial (see Figure 2). A wireless audio receiver (Azden Corporation, model WR-PRO) was mounted on each video camera, and an audio transmitter (Peak Performance Technologies Inc., model Remote Video Synchronization Unit) sent out a synchronizing tone that was recorded on the audio track of each video recording. This recorded audio tone was used to synchronize the recording data of each video camera. 


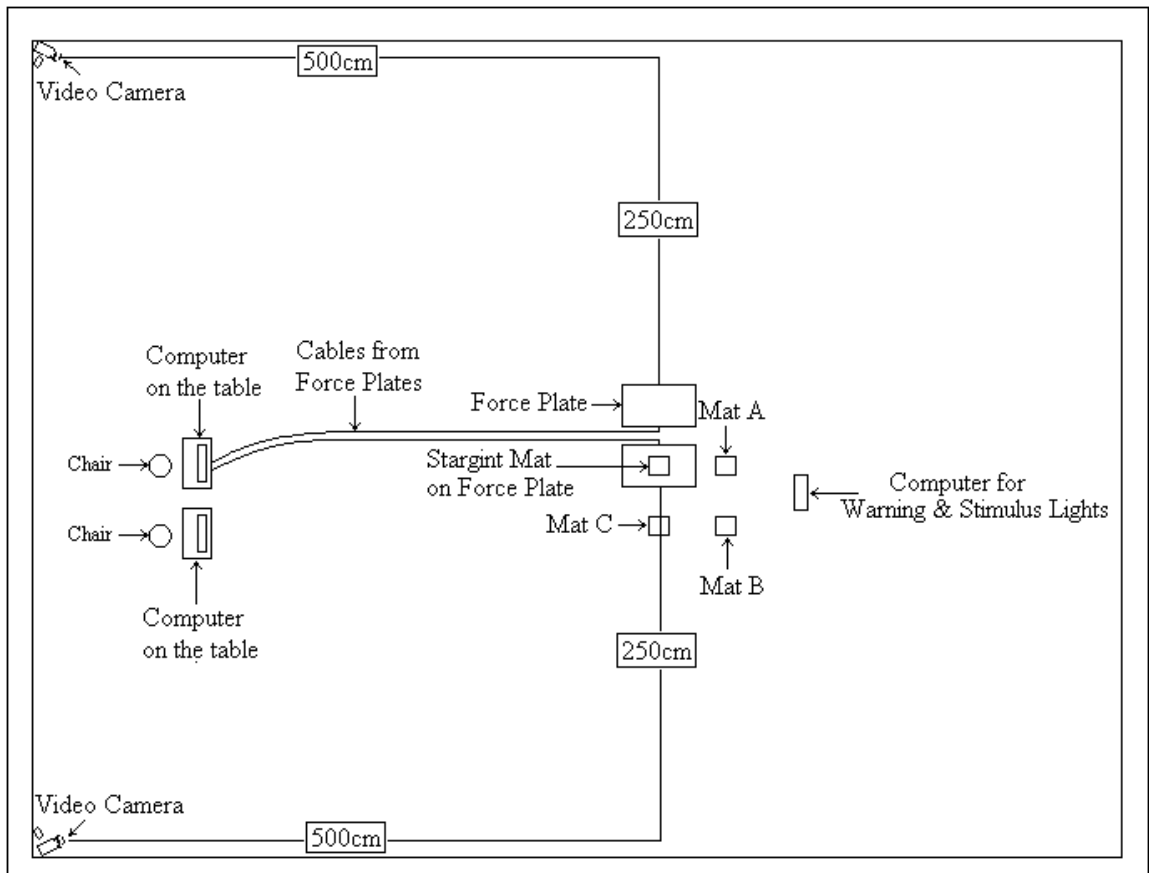

Figure 2. Schematic for laboratory system including all devices relevant to the conduct of the experiment.

Force plate. Two force plates (Kistler Group, model 9286AA) were used to determine simple reaction time of the feet by analyzing vertical ground reaction force data. The force plates enabled measurement of the shifting weight, known as ground reaction force, within three axes $(\mathrm{x}, \mathrm{y}$, and $\mathrm{z})$ and sent the data to the connected computer.

Synchronizing system. The Vicon Motus Video digitizing system (Vicon, model Vicon Motus 9.2) received the digital images from each video camera and synchronized them with the data from vertical ground reaction force of the force plate for detecting each frame of the data from the force plates at the moments when the DataLOG began wirelessly transferring EMG data, the warning light turned on, and the stimulus light turned on. 
Target location. The starting mat $(10.4 \mathrm{~cm} \times 10.4 \mathrm{~cm})$ on the force plate was placed under a participant's chosen foot (right or left), and Mat A, Mat B, and Mat C $(10.4 \mathrm{~cm} \times 10.4 \mathrm{~cm})$ were set on the floor to form a rectangle with the starting mat. The distance from the starting mat to Mat A as well as from Mat B to Mat C was $32.7 \mathrm{~cm}$, and the distance from the starting mat to Mat $\mathrm{C}$ as well as from Mat A to Mat B was $30.5 \mathrm{~cm}$. Therefore, the diagonal distance from the starting mat to Mat B as well as from Mat A to Mat $\mathrm{C}$ was $43.5 \mathrm{~cm}$ (see Figure 3).

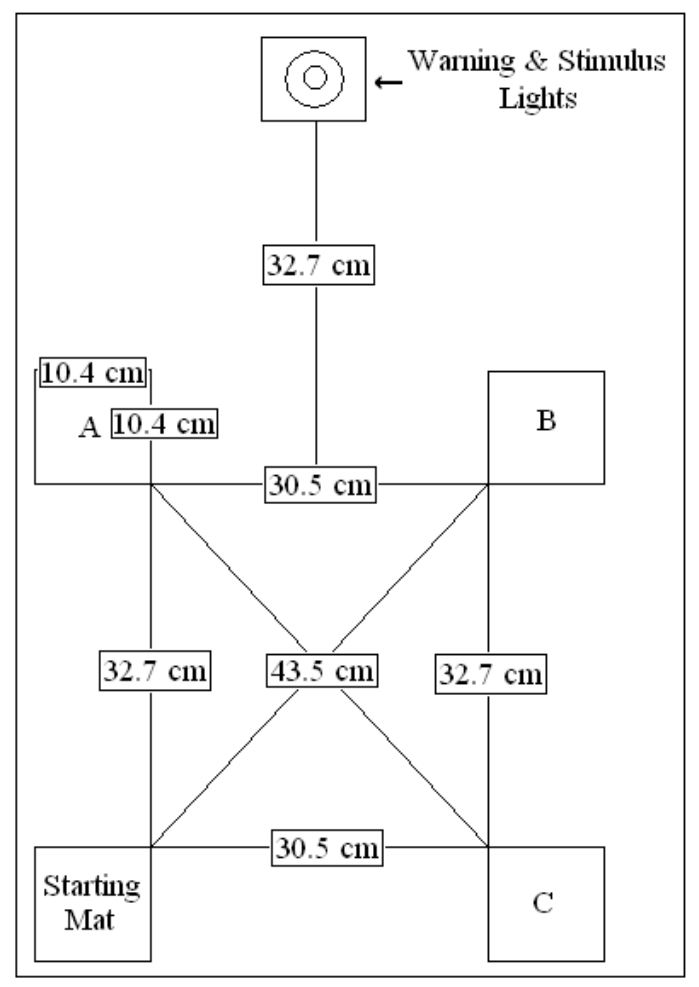

Figure 3.Schematic of experimental setting including mats, warning signals, and stimulus lights. 
Warning and stimulus lights. The warning and stimulus lights were programmed by the National Instruments LabVIEW 7.0 in a laptop computer. A dark green colored circle which was $15 \mathrm{~cm}$ in diameter was displayed on a computer screen. A white colored circle which was $5 \mathrm{~cm}$ in diameter was displayed on the center of the green circle as a warning light after clicking a start button on the screen. A light green color was filled a remaining dark green colored area as a stimulus light after the warning light. The time between the start button and the warning light as well as the warning light and the stimulus light (foreperiod) was randomized by the program for preventing the anticipation of the warning and stimulus lights by the participants. The computer was set at $32.7 \mathrm{~cm}$ away from the middle point between Mat A and Mat B (see Figure 3).

Mouth guard. A self-adapted mouth guard is the most popular mouth guard and accounts for $90-95 \%$ of the market share of all mouth guard users (Woodmansey, 1997). Therefore, the self-adapted mouth guard was used in this study, and the $\mathrm{LP}+{ }^{\mathrm{TM}}$ MOUTHGUARD (Brain Pad Inc.) was selected for the following reasons: readily available and easy to shape. This mouth guard can be purchased with less than $\$ 10$ at a sporting goods department in a commercial shopping center. It also comes with a wellexplained and well-illustrated fitting instruction which allows the participants to easily shape the mouth guards. Each participant received the mouth guard on the day they participated in the experiment, and they shaped it to their teeth after individually entering the experimental room. If a participant felt any discomfort of wearing the shaped mouth guard or if a participant failed to shape the mouth guard, a new mouth guard was provided to the participant. 
Alcohol pad, disposable razor, and abrasive pad. Alcohol pads, disposable razors, and abrasive pads were used for cleaning up and shaving off any hair or dead skin cells as a preparation for placing the surface electrodes. The pad and the razor were discarded into a disposal container after being used.

\section{Presentation of the Movement Used for Data Collection}

From the standpoint of movement complexity, the depiction of the tasks used by the Henry and Rogers' study (1960) was debated by Klapp (1980). Klapp's contention was that the movements used in the Henry and Rogers' study were nothing more than large movements and did not mean they were complex movements. In fact Henry and Rogers failed to define what the complexity of movement was and to provide the information how Movement A, B, and C differed from each other in complexity.

The index of difficulty (ID) is a formula which can define the complexity of movement. This formula was derived from Fitts' law developed from the speed-accuracy trade-off by Paul Fitts in 1954 (Fitts, 1954; Magill, 2006; Schmidt \& Wrisberg, 2000). The formula of the ID is constructed from $\log _{2}(2 \mathrm{D} / \mathrm{W})$ which $\mathrm{D}$ indicates a distance between a starting point and a target, and $\mathrm{W}$ indicates a width of the target. It shows that the higher number of the ID is more difficult to perform (Magill, 2006).

By using the ID, the complexity of movement in the Henry and Rogers' study (1960) can be described. According to Fischman, Christina, and Anson (2008), the distance from the center of the ball (Ball $\mathrm{B}$ and Ball C) to the base was $15.2 \mathrm{~cm}$. The points, where the centers of each ball intersect at the base, formed a square with the reaction key and the dummy button on the base, and the side of the square was $20.3 \mathrm{~cm}$. 
By using these dimensions, the diagonal distance can be calculated. The diagonal distance from the reaction key to Ball B as well as from the dummy button to Ball C was $25.4 \mathrm{~cm}$, and the diagonal distance from the reaction key to Ball $\mathrm{C}$ as well as from the dummy button to Ball B was $32.5 \mathrm{~cm}$ (see Figure 4). To use the ID formula, the distance has to be between the edges of starting and ending points. Therefore, the radius of the ball $(3.5 \mathrm{~cm})$ has to be subtracted from these diagonal distances. As the result of the subtraction, the diagonal distance from the reaction key to Ball B as well as from the dummy button to Ball $\mathrm{C}$ was $21.9 \mathrm{~cm}$, and the diagonal distance from the reaction key to Ball $\mathrm{C}$ as well as the dummy button to Ball B was $29 \mathrm{~cm}$ (see Figure 5). With these diagonal distances and the diameter of the ball $(6.9 \mathrm{~cm})$, the ID for each movement can be calculated, and these IDs were 0 for Movement A, 2.7 for Movement B, and 8.8 for Movement C. Therefore, these IDs can confirm that each movement in the Henry and Rogers' study had properly introduced complexity to their experiment. 


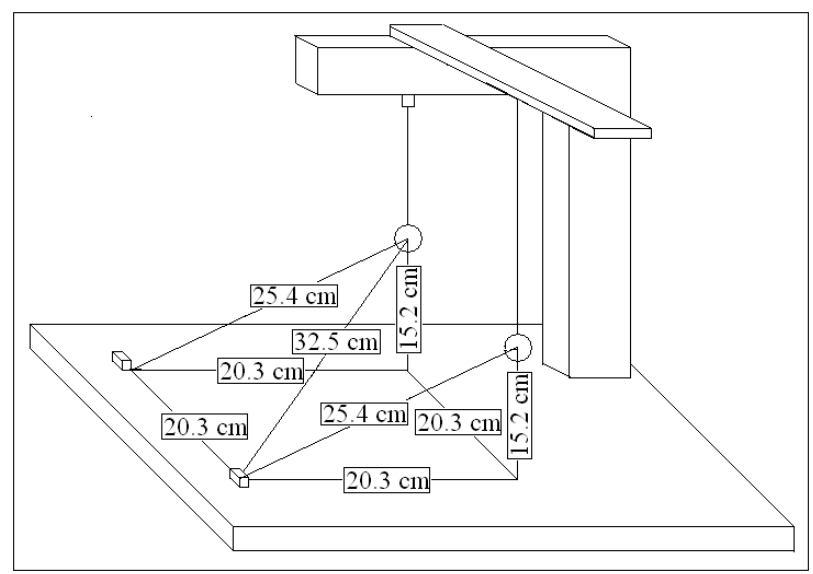

Figure 4. Adaptation of Henry and Rogers' apparatus with distances; reprinted with permission from Research Quarterly for Exercise and Sport, Vol. 79, No. 3, 312-318 (pages), Copyright (2008) by the American Alliance for Health, Physical Education, Recreation and Dance, 1900 Association Drive, Reston, VA 20191. (Appendix B).

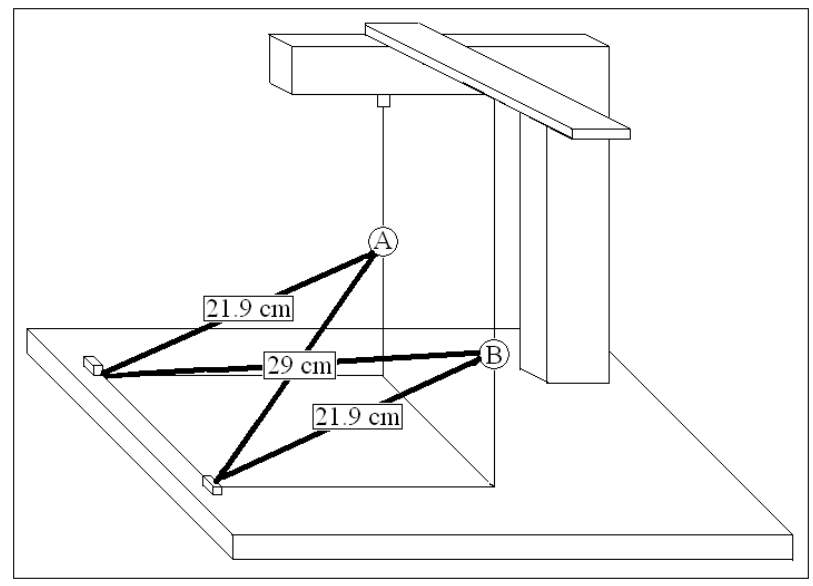

Figure 5. Adaptation of Henry and Rogers' apparatus with distances for movements; reprinted with permission from Research Quarterly for Exercise and Sport, Vol. 79, No. 3, 312-318 (pages), Copyright (2008) by the American Alliance for Health, Physical Education, Recreation and Dance, 1900 Association Drive, Reston, VA 20191 (see Appendix B). 
The ID for the current study replicated the IDs from the Henry and Rogers'study (1960) however as it applied to lower extremity movements. The starting mat and Mat A, $\mathrm{B}$, and $\mathrm{C}$ were placed on the floor in order to form a rectangle. The distance from the starting mat to Mat A as well as from Mat B to Mat C was $32.7 \mathrm{~cm}$, and the distance from the starting mat to Mat C as well as from Mat A to Mat B was $30.5 \mathrm{~cm}$. Therefore, the diagonal distance from the starting mat to Mat B as well as from Mat A to Mat $\mathrm{C}$ was $43.5 \mathrm{~cm}$ (see Figure 6). With the side of the rectangle $(32.7 \mathrm{~cm})$, the diagonal distance $(43.5 \mathrm{~cm})$, and the width of the mat $(10.4 \mathrm{~cm})$, the ID for each movement were calculated, and these IDs were 0 for a low complexity movement, 2.7 for a moderate complexity movement, and 8.8 for a high complexity movement. Therefore, the IDs for the low, moderate, and high complexity movements in the current study were identical with the IDs for Movement A, B, and C in the Henry and Rogers' study.

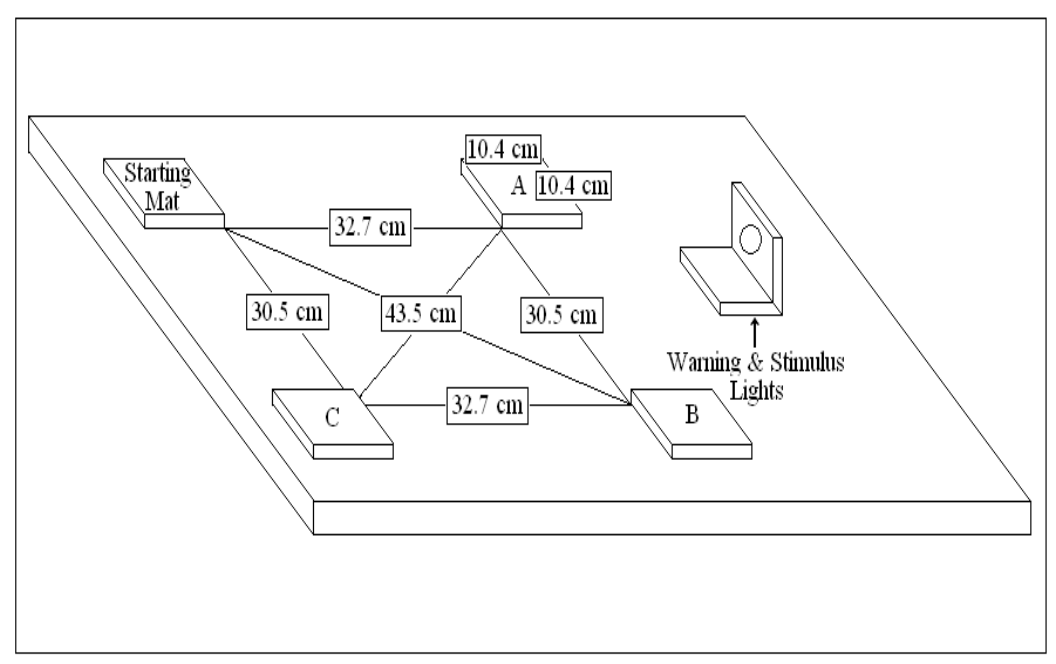

Figure 6. Schematic representing the distances between adjacent targets. 


\section{Organization of Procedures Used in the Experiment}

Prior to the experiment, a consent form (Appendix C) was given to each participant explaining the purpose of the study and the possible risks during participation in the study. The study conformed to the guidelines set for ethical standards in research and was approved by the San José State University Institutional Review Board (Appendix D) prior to data collection. Any questions with regard to the study were answered by the primary researcher before, during, and after the study. A code was assigned to each participant to protect the confidentiality of personal information, and the codes and names from the participants were known only to the primary researcher. Participants were asked to wear t-shirts, shorts, socks, and athletic shoes which are used for physical activity, and any brace or tape on their body (e.g., ankle or knee brace and ankle tape) that is normally used were allowed.

Each participant was tested individually in an area set up for the experiment to prevent him from gaining feedback or information about the experiment from other participants. Once the participant was taken to the experimental room, a self-adapted mouth guard (Brain Pad Inc., model LP+ ${ }^{\mathrm{TM}}$ MOUTHGUARD) was given to him. The participant shaped the mouth guard by following the written instructions that came with

the mouth guard. After shaping the mouth guard, one of the audio instructions (Appendix E), depending on the order of the movement complexity and the order of mouth guard condition, was played to help the participant understand the procedures of the experiment. The participant chose which foot (right or left) he preferred to use for the tasks, and the side of the foot that the participant chose was recorded. After the participant's preferred 
foot was identified, the participant wiped off with alcohol pads, shaved any hair with a disposable razor, and rubbed with abrasive pads on the areas which were masseter muscles, the distal end of vastus medials muscle, and the muscle belly of the gastrocnemius muscle on right and left legs. Once the preparation was completed, and all pads and the razor were discarded by the participant, surface EMG electrodes were applied on the areas, the DataLOG was attached to the participant's lower back by the belt, and the cables from each surface EMG electrodes were connected to the DataLOG. The primary researcher demonstrated the movement before each task, and the participant performed one practice trial to become familiar with the task and its complexities prior to each trial. When the participant needed more demonstration or information regarding the movement, the primary researcher showed additional demonstrations and answered the questions before the participant started to perform the recording trials.

For the low complexity movement, the participants stood on a starting mat on the force plate with their preferred foot and on the other force plate with the non-preferred foot. The stance of the feet was set as the participants' preferred stance but slightly wider than the distance of their shoulders. Then the participants were asked to adopt an upright posture with open hands (approximately $45^{\circ}$ shoulder abduction) and slightly bent knees (approximately $45^{\circ}$ knee flexion) (see Figure 7). From this position, the participants were instructed to lift their preferred foot as quickly as possible from the starting mat in response to the stimulus light (see Figure 8). During the time interval from the appearance of the warning light to the initiation of lifting the preferred foot from the 
starting mat, the data from the force plates and the fractionated reaction times from each electrode were recorded.

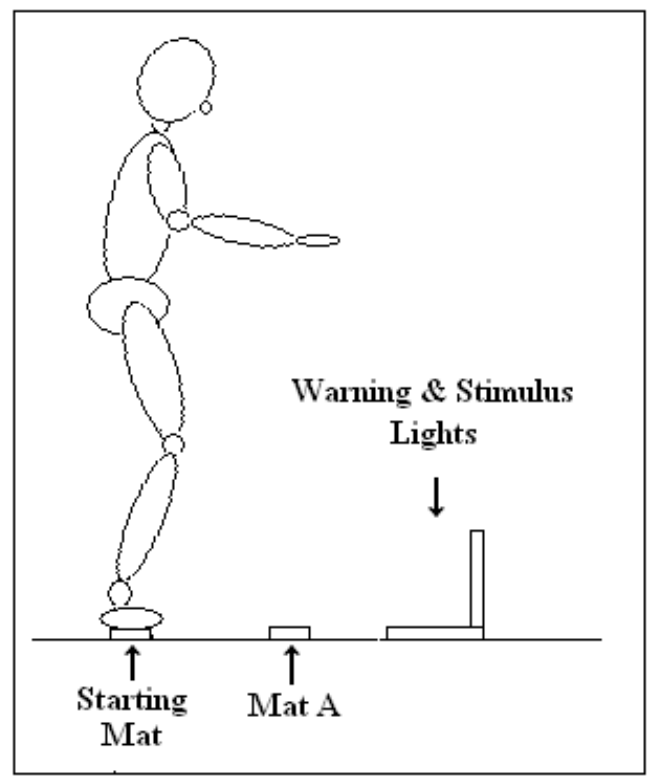

Figure 7. The position of participant: participants were asked to assume an upright posture with open hands (approximately $45^{\circ}$ shoulder abduction) and slightly bent knees (approximately $45^{\circ}$ knee flexion). 


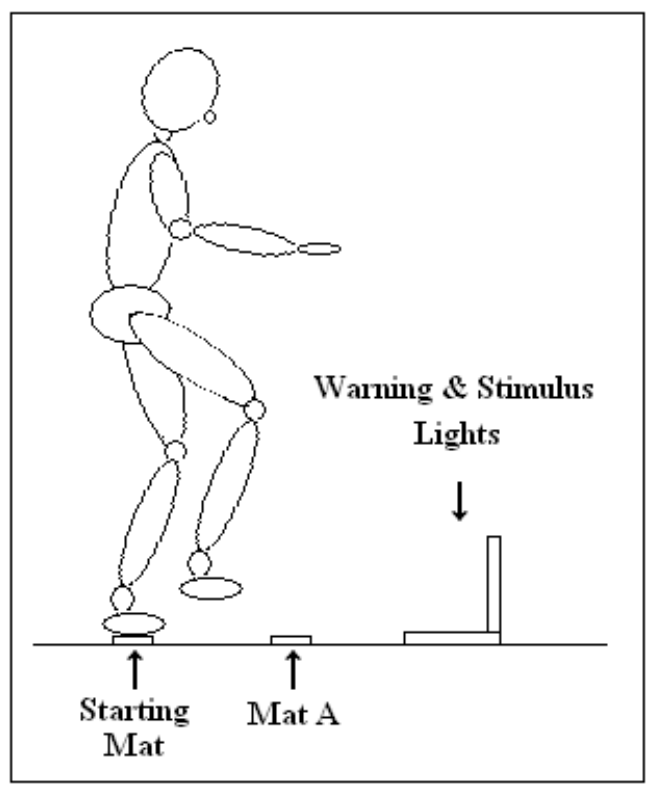

Figure 8. Low complexity movement: participants were instructed to lift their preferred foot from the starting mat in response to the stimulus light as quickly as possible.

For the moderate complexity movement, the participants stood on the starting mat on the force plate with their preferred foot and on the other force plate with the nonpreferred foot. The participants were asked to adopt the same stance and posture as the low complexity movement (see Figure 7). From this position, the participants were instructed to lift their preferred foot from the starting mat in response to the stimulus light and to move as quickly as possible the foot forward to step on Mat A (see Figure 9). During the time interval from the appearance of the warning light to the initiation of lifting their preferred foot from the starting mat, the data from the force plates and the fractionated reaction times from each electrode were recorded. 


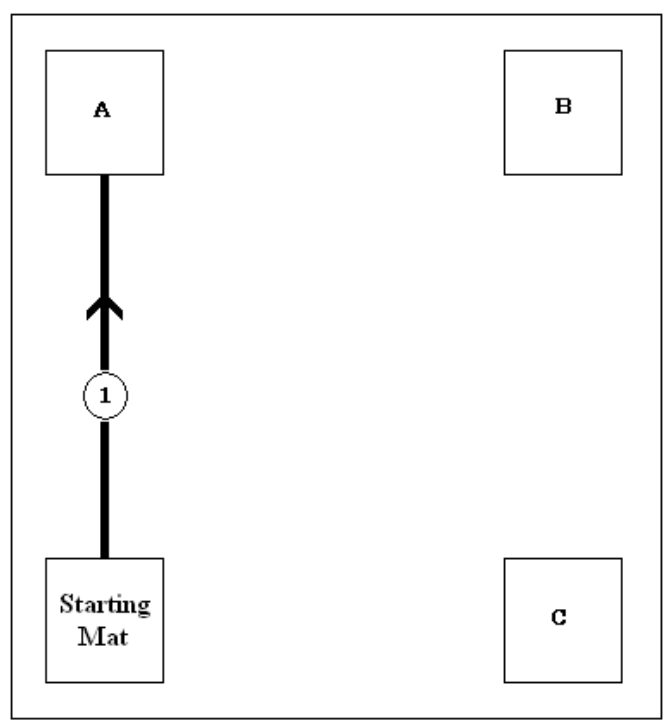

Figure 9. Moderate complexity movement: Participants moved the preferred foot forward to step on Mat A.

For the high complexity movement, the participants stood on the starting mat located on the force plate with their preferred foot and on the other force plate with the non-preferred foot, and they also adopted the same stance and posture as low and moderate complexity movements (see Figure 7). From this position, the participants were instructed to lift their preferred foot from the starting mat in response to the stimulus light, to move the foot diagonally forward to step on Mat B, to move the foot backward to step on Mat C, and to move the foot diagonally forward to step on Mat A (see Figure 10). The participants were asked to complete the series of movements as quickly as possible. During the time interval from the appearance of the warning light to the initiation of removing their preferred foot from the starting mat, the data from the force plates and the fractionated reaction times from each electrode were recorded. 


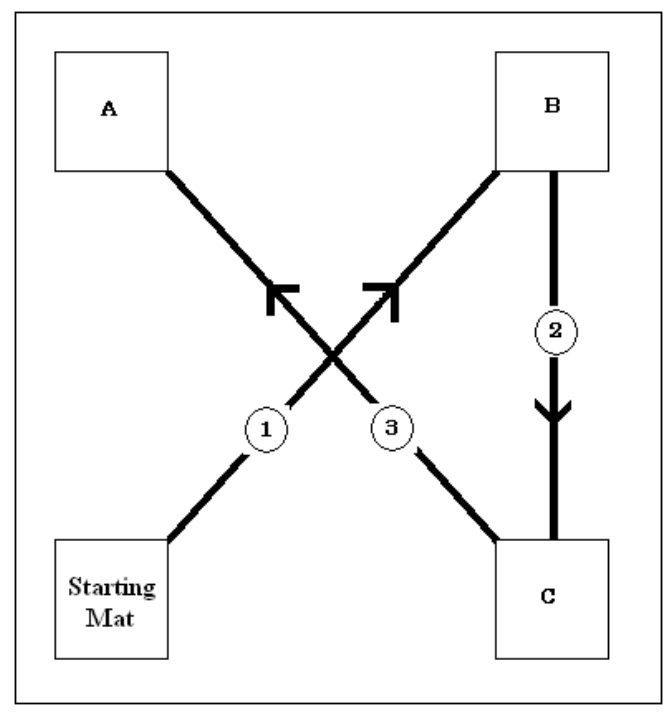

Figure 10. High complexity movement: Participants moved forward and to the right to step on Mat B (1), moved backward to step on Mat C (2), and moved diagonally forward and to the left to step on Mat A (3).

\section{Presentation of the Design}

Each participant performed 10 trials with one practice trial under each mouth guard condition (wearing a self-adapted mouth guard and not wearing a mouth guard) and across each task (low, moderate, and high complexity movements). Two conditions led to errors: a reaction before the appearance of the stimulus (anticipation) and the failure to complete the movement (e.g., failure to step on any mat). A trial which resulted in error was repeated after completed to perform 10 trials on the movement. The independent variable mouth guard condition and movement complexity were both within subject measures. They were both counterbalanced across participants using a Latin Square design as illustrated Table 1. 


\section{Table 1}

Research Design from Crossing the 2 (Mouth Guard Conditions) by 3

(Movement Complexity) with Repeated Measures on Both Factors

\begin{tabular}{lccccccc}
\hline Group & Cond. 1 & Cond. 2 & Cond. 3 & Cond. 4 & Cond. 5 & Cond. 6 & $\mathrm{n}$ \\
\hline 1 & Lm & Mm & Hm & Lnm & Mnm & Hnm & 2 \\
2 & Mm & Hm & Lnm & Mnm & Hnm & Lm & 2 \\
3 & Hm & Lnm & Mnm & Hnm & Lm & Mm & 2 \\
4 & Lnm & Mnm & Hnm & Lm & Mm & Hm & 2 \\
5 & Mnm & Hnm & Lm & Mm & Hm & Lnm & 2 \\
6 & Hnm & Lm & Mm & Hm & Lnm & Mnm & 2
\end{tabular}

Note . Cond. $=$ Condition. $\mathrm{L}=$ low complexity movement. $\mathrm{M}=$ moderate complexity movement. $\mathrm{H}=$ high complexity movement. $\mathrm{m}=$ wearing a mouth guard. $\mathrm{nm}=$ not wearing a mouth guard. $\mathrm{n}=$ Number of participants.

Fractionated reaction time is composed of two components. The first component is the premotor component, which indicates the cognition of the stimulus and the preparation of the muscle for the task. The second component is the motor component, which indicates the muscular activity prior to the actual movement of the task (Magill, 2006). To measure the fractionated reaction time enables to understand which factor affects causing the simple reaction time shorter or longer.

\section{Procedures for Statistical Analysis}

A 2 way ANOVA with repeated measures on both factors was conducted to analyze simple reaction time. Specifically a 3 (movement complexity) x 2 (mouth guard condition) within subject design was used to analyze the simple reaction times determined by using ground reaction force data measured by a force plate and video data 
captured by a single video camera. Moreover, fractionated reaction time was measured in masseter, vastus medialis, and gastrocnemius muscles within two mouth conditions on three whole body movements of varying complexity (low, moderate, and high complexity movements). The level of statistical significance was set at less than 0.05 in an analysis of variance (ANOVA) to assess statistically significant differences.

\section{Specific Data Selected for Analysis}

A force plate (Kistler Group, model 9286AA) was utilized to collect ground reaction force data. These data were used to determine the length of simple reaction time. The force plate has a sampling rate of 600 samples per second enabling the measurement of the shifting weight as known as ground reaction force within three axes $(\mathrm{x}, \mathrm{y}$, and $\mathrm{z})$. In the current study, vertical ground reaction force (z axis) from the participant's preferred foot was utilized to calculate the simple reaction time by synchronizing data from video data captured by a single video camera. The raw analog data of vertical ground reaction force from the Vicon Motus system were converted to a Microsoft Office Excel file for graphing purposes. To identify when the preferred foot initially started moving from the force plate in the graph, the average vertical ground reaction force of the preferred foot on a trial was calculated from the point where a linear line on the graph started after the warning light turned on, to a point where the linear line started ascending after the stimulus light turned on. This average vertical ground reaction force was set as a baseline. The initial movement as known as simple reaction time was defined as the point where the ascending line of the graph passed 10 Newtons greater than the baseline of vertical ground reaction force. Through the calculation, it was found that the entire 
ground reaction force data from one of 12 participants was unreadable due to technical difficulty. Therefore, his data were excluded from further data analysis. To avoid adding extreme simple reaction times that were too short or too long in the process of analyzing data, standard deviations (SD) of each movement while wearing a self-adapted mouth guard and not wearing a mouth guard from 11 participants were calculated. The simple reaction times which were out of SD1 $(68 \%)$ were excluded, and the mean of the remaining simple reaction times of each movement while wearing a self-adapted mouth guard and not wearing a mouth guard from 11 participants were utilized for further data analysis.

Surface electrodes (Biometrics Ltd., model SX230 EMG Sensor) were placed on both masseter muscles above the angle of the mandibular bone, over the distal end of vastus medialis muscles, and over the muscle bellies of the gastrocnemius on both legs with a sampling rate of 1000 samples per second. The EMG data collected by the DataLOG device (Biometrics Ltd., model W4X8) were wirelessly transferred to the Biometrics Analysis Software (Biometrics Ltd., model v7.5). The data were rectified and filtered with $6 \mathrm{~Hz}$ cutoff frequency to smooth the data. By using ground reaction force of $\mathrm{z}$ axis from the preferred foot and data from digital images of a video camera, the smoothed data were divided into four parts which were the time when the EMG started to collect, the time when the warning light turned on, the time when the stimulus light turned on, and the time when the participant initially started to move his preferred foot. By using the divided four parts from the smoothed data, the premotor and motor reaction times were calculated. Through the calculation, it was found that all participants 
activated their lower extremities' muscles before the stimulus light turned on and thus premotor and motor components of reaction time could not be determined. The EMG data from all participants were excluded from the data analysis.

\section{Discussion of the Dependent Variable}

“Memory drum" theory was presented by Henry and Rogers (1960), and it revealed the relationship between simple reaction time and movement complexity. In their study, they found that there were mean simple reaction times of $0.144,0.186$, and 0.199 s for Movement A (simple), Movement B (moderate), and Movement C (complex) respectively. In contrast the mean simple reaction times of the current study were shown to be $0.145,0.150$, and $0.191 \mathrm{~s}$ when collapsed across mouth guard condition for the low complexity movement (simple), the moderate complexity movement (moderate), the high complexity movement (complex) respectively. These simple reaction times were somewhat shorter than the simple reaction times of Henry and Rogers' study. One possibility for the reason why the simple reaction times recorded in current study were shorter than Henry and Rogers' study may be the moment where each study records the onset of the movement and the end of the reaction time. In Henry and Rogers' study, participants lifted their finger form the reaction key which was activated when the weight of the finger released from the key, therefore, the simple reaction time was recorded at somewhere between the point where the load of weight on the reaction key was under the weight of the finger and the point where the finger was completely released from the reaction key (see Figure 11). While observing the video data captured by a single video camera and vertical ground reaction force which were converted to a Microsoft Office 
Excel in the current study, the movement to lift the preferred foot was initiated from pushing down the force plate followed by lifting the foot. Therefore, the simple reaction time of the current study was recorded when the participants' weight of the preferred foot increased (pushed down the force plate) 10 Newtons from the average weight (see Figure 11). The differences between the time to record the phase of pushing down and the phase of lifting up were attributed to the differences of simple reaction time on both studies.

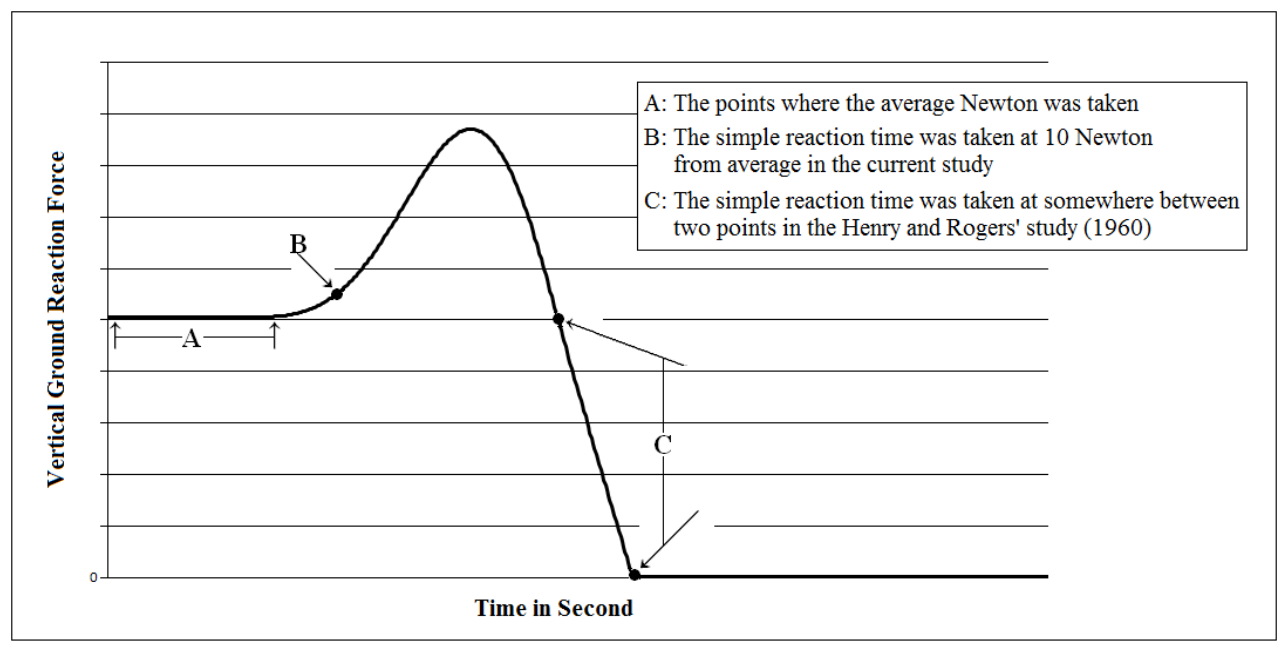

Figure 11. Comparison of the sampling rates for this study and Henry and Rogers' study (1960).

\section{Summary}

The purpose of this study was to investigate if there was a difference in simple reaction time among low, moderate, and high complexity movements under two mouth guard conditions (wearing a self-adapted mouth guard and not wearing a mouth guard). Participants performed a total 66 trials of a whole body movement. To investigate the difference between simple reaction times among three movements under two mouth guard conditions, the data from the simple reaction times determined by using vertical 
ground reaction force data from the force plate and video data captured by a single video camera as well as from the EMG of the vastus medialis muscle and gastrocnemius muscle on the preferred foot were analyzed. 


\section{Chapter 4}

\section{Results}

In the present study the hypothesis advanced by Henry and Rogers (1960) in the "memory drum" theory was investigated. The purpose of the investigation was to study the effects of movement complexity (with three varying complexities) across two mouth guard conditions (when participants were either wearing a self-adapted mouth guard or not wearing a mouth guard) to study their impact on simple reaction time. Simple reaction time was determined using vertical ground reaction force data measured by a force plate. Video data captured by a single video camera were digitized to verify the onset of movement. In this chapter the results from the analysis of variance are presented.

\section{Presentation of the Results from the Analysis of Variance}

Presented in Table 2 is the source table for the two-way ANOVA resulting in a 2 (mouth guard condition) x 3 (movement complexity) within subject analysis of variance conducted to study the effects of crossing these conditions on simple reaction time data. The analysis revealed a significant interaction of mouth guard condition by movement complexity, $F(1,10)=45.56, p<.001$, and a significant main effect of movement complexity, $F(1,10)=8.56, p<.05$. The significant movement complexity main effect helps to partially explain the interaction effect. The mean simple reaction time for the high complexity movement while wearing a self-adapted mouth guard and not wearing a mouth guard was longer as compared to the simple reaction time for low and moderate complexity movements while wearing a self-adapted mouth guard and not wearing a mouth guard as indicated in the means. Approximately $82 \%$ of the variance in simple 
reaction time can be explained by knowing movement complexity, a substantial effect $($ eta $=.91)$. When the variables are plotted as depicted as in Figure 11, the interaction of mouth guard condition by movement complexity may be explained in the differences in performance when a participant is wearing a self-adapted mouth guard and when not wearing a mouth guard for low and moderate complexity movements. Participants reacted faster when wearing a self-adapted mouth guard than when not wearing a mouth guard for the simple and moderate movements (low and moderate complexity movements) but not for the complex movement (high complexity movement) (see Table 3). As shown in the Henry and Rogers' study (1960), the differences between conditions were calculated by using the mean of the simple reaction times. Collapsed across mouth guard condition, the moderate complexity movement required $3 \%$ longer simple reaction time than the low complexity movement, and the high complexity movement required $22 \%$ longer simple reaction time than the moderate complexity movement. 
Table 2

ANOVA Summary Table of the 2 (Mouth Guard Conditions) by 3 (Movement Complexity) Within Subject ANOVA

\begin{tabular}{lccc}
\hline \multicolumn{1}{c}{ Source } & df & MS & F \\
\hline Mouth guard & 1 & 0.001 & 1.61 \\
Error (Mouth guard) & 10 & 0.001 & \\
Complexity & 1 & 0.023 & $45.561^{*}$ \\
Mouth guard x complexity & 1 & 0.001 & $8.557^{* *}$ \\
Error (Mouth guard x complexity) & 10 & 0.000 & \\
\hline Note. ${ }^{*} \mathrm{p}<.001 .{ }^{* *} \mathrm{p}<.05$. & & & \\
\hline
\end{tabular}

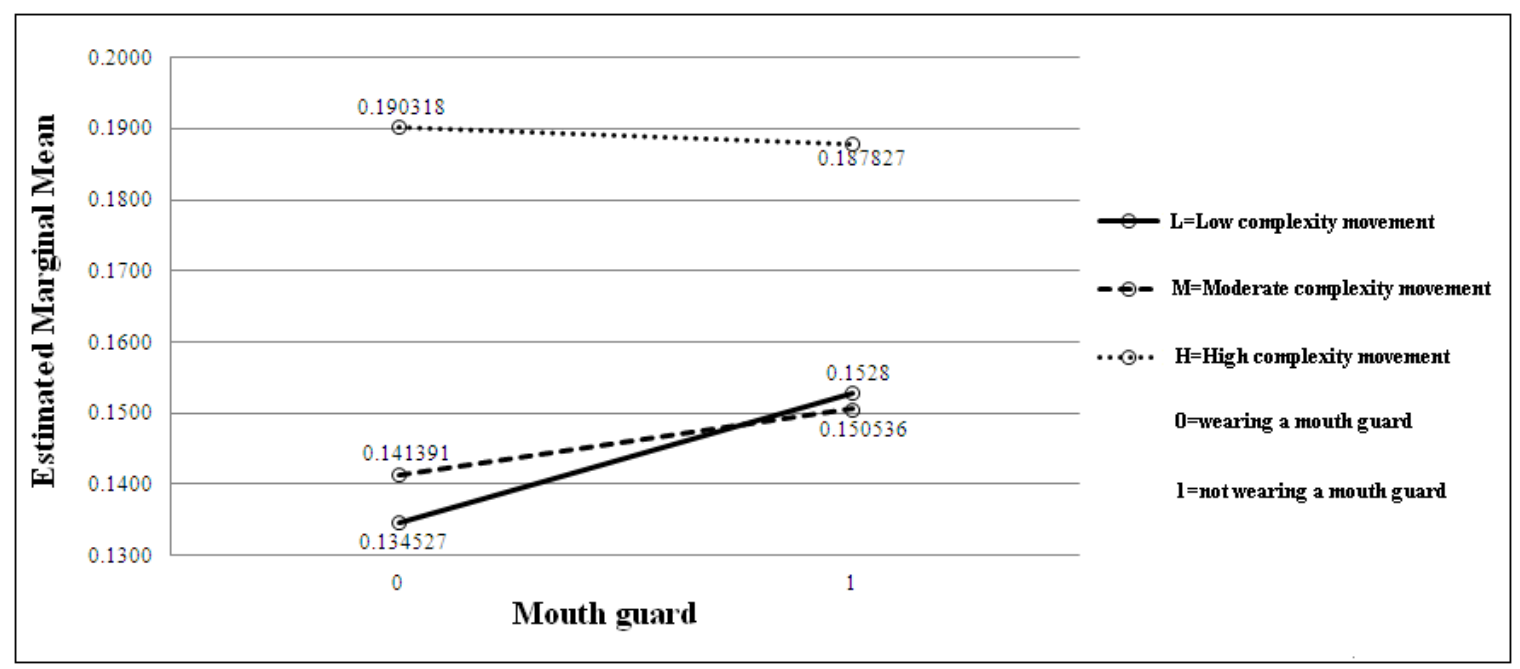

Figure 12. Significant interaction of mouth guard condition by movement complexity. 


\section{Table 3}

Means and Standard Deviations from the 2 (Mouth Guard)

by 3 (Movement Complexity) Conditions

\begin{tabular}{cccc}
\hline & Mean & Standard Deviation & $\mathrm{n}$ \\
\hline RTL0 & 0.13453 & 0.0299751 & 11 \\
RTM0 & 0.14139 & 0.0284783 & 11 \\
RTH0 & 0.19032 & 0.340851 & 11 \\
RTL1 & 0.1528 & 0.02387 & 11 \\
RTM1 & 0.15054 & 0.0256427 & 11 \\
RTH1 & 0.18783 & 0.0253816 & 11 \\
& & \\
\hline $\begin{array}{l}\text { Note. RT = Reaction time. L = low complexity movement. M = moderate complexity movement. } \\
\text { H = high complexity movement. } 0=\text { wearing a mouth guard. } 1=\text { not wearing a mouth guard. } \\
\mathrm{n}=\text { Number of participants }\end{array}$
\end{tabular}




\section{Chapter 5}

\section{Discussion}

Henry and Rogers (1960) proposed that increases in movement complexity result in changes in simple reaction time in the "memory drum" theory. They suggested that these changes are reflective of the motor programming required as movement becomes more complicated. In this experiment, their hypothesis was tested across two mouth guard conditions. Simple reaction time was measured by the vertical ground reaction force data measured by a force plate and through video analysis to capture the onset of movement. Presented in this chapter are a discussion of the results, a statement of conclusion, recommendations for future study, and a summary.

\section{Discussion of the Results}

The study was developed to determine whether wearing a mouth guard would affect reaction time performance on a series of whole body movements. Further, the study was designed to examine the hypothesis provided by Henry and Rogers (1960) in their "memory drum" theory that more complicated movement requires longer reaction times than simple movement.

Included in the experiment were 12 college aged male participants currently enrolled in a kinesiology major, all had some experience playing sports and were free from injury. Reaction time was determined to be the moment of ground reaction force in the vertical dimension as measured by a force plate and by capturing video to verify the movement of ground reaction force. Although the methods included measurement of EMG to be able to disaggregate premotor and motor reaction time from the reaction time 
phase, unfortunately the data of EMG were unreadable due to noise in the system caused by the starting posture (the stance slightly wider than the distance of their shoulders, the upright position with open hands, and slightly bent knees).

Three null hypotheses were adopted at the outset of the study. The null hypothesis that mouth guard condition does not affect simple reaction time of a whole body movement was accepted. When collapsed across movement complexity, no statistically significant effect of mouth guard was uncovered in this study. The null hypothesis that movement complexity does not affect simple reaction time was rejected. A statistically significant effect of movement complexity indicated that participants had longer reaction times while performing the high complexity movement than while performing the low and moderate complexity movements that showed a very similar simple reaction time. The null hypothesis that mouth guard condition and movement complexity do not interact to affect simple reaction time was rejected. A statistically significant interaction effect indicated that participants had longer reaction times while performing the high complexity movement than their reaction times while performing the low and moderate complexity movements across both mouth conditions. Further, participants reacted somewhat faster on the low and moderate complexity movements when wearing a self-adapted mouth guard than when not wearing a mouth guard.

In this study simple reaction time performance was slowest for the most complex of the three movements (High complexity movement for both mouth guard conditions partially supporting the notion of Henry and Rogers in 1960). This phenomenon can be explained by using the notions of other researchers. According to Anson (1982), the 
increase in the anatomical unit involved, which is the number and size of a body part exerted to perform a movement, reduces simple reaction time due to increased electromechanical delay. On the low and moderate complexity movements in the current study, participants required only ankle dorsiflexion and plantarflexion, knee flexion and extension, and hip flexion and extension. On the high complexity movement, in contrast, participants required abduction, adduction, and internal and external rotation of the hip in addition to the same motions required for the low and moderate complexity movements. These extra motions for the high complexity movement might cause increasing electromechanical delay, and therefore simple reaction time for the high complexity movement might be longer than the others. The notion of Christina et al. (1982) can also explain why simple reaction time for Movement $\mathrm{C}$ became the longest of all. The researchers mentioned four characteristics of a movement that might reduce the speed of simple reaction time: duration of movement, accuracy of movement, directional change in movement, and distance of movement. The high complexity movement in the current study required participants to step accurately on three targets with their preferred foot in a specific order. The high complexity movement also required more directional changes of the movement and, therefore it had a longer distance to complete the movement than the low and moderate complexity movements. Because of many directional changes and a long distance to complete the high complexity movement, participants reacted slower to the high complexity (long duration of the movement) than the low and moderate complexity movements. These four characteristics of a movement mentioned by Christina et al. apply perfectly to the high complexity movement in the current study, and 
these characteristics can explain why simple reaction time for the high complexity movement was longer than the simple reaction time for the low and moderate complexity movements.

Further in this study, participants reacted faster for the simple movement (low complexity movement) and moderate movement (moderate complexity movement) while wearing a self-adapted mouth guard than while not wearing a mouth guard, but it was not apparent for the high complexity movements. This trend might be explained by using the findings of former studies. Ishijima, Hirai, Koshino, Konishi, and Yokoyama (1998) and Morozumi et al. (2004) investigated the effect of dentures on simple reaction time for older adult participants. Ishijima et al. tested elderly participants who did not have teeth at all and found that wearing dentures resulted in significantly shorter reaction time than not wearing dentures while performing a task that was to jump in response to a stimulus light. Morozumi et al. tested older adult participants from three groups: those with no teeth at all, those with no teeth in one jaw and some teeth in the other jaw, and those with some teeth in both jaws. They found that the condition of clenching with dentures produced significantly shorter reaction time than the condition of clenching without dentures on a jumping task when responding to a stimulus light. There was significant improvement in reaction time on the relatively dynamic movement (jumping) while clenching dentures compared with the other conditions (clenching without dentures, opening mouth with dentures, and opening mouth without dentures) but no significant improvement in reaction time on the non-dynamic movement (lifting feet from the floor at sitting position when responding to a stimulus light) within all conditions. Ishijima et 
al. (1998) suggested that wearing dentures stabilizes the mandibular position and thus affects the required reaction time on a jumping task. A mouth guard has a similar effect on the mandibular position by filling spaces where there are no teeth (Vastardis, 2005). Stabilizing the mandibular position might reduce the electromechanical delay. In the current experiment wearing a self-adapted mouth guard led to shorter simple reaction times than not wearing a self-adapted mouth guard on the low and moderate complexity movements but not on the high complexity movements. A possible explanation for this phenomenon is that the complicated movements distracted the participants from moving as quickly as possible on their first motion of the high complexity movement. The change in simple reaction time across the mouth guard conditions might be too small to find a significant difference when reaction time is longer as in the high complexity movement.

The current study was designed to determine how use of a mouth guard and movement complexity affect reaction time and further to examine Henry and Rogers' hypothesis (1960) that complexity of movement affects simple reaction time by performing lower extremity movements. Even though the relationship between use of a mouth guard and simple reaction time had been studied by Bourdin et al. (2006), theirs was limited to a small upper extremity movement (pressing a button as response to a stimulus). Moreover, the Henry and Rogers' hypothesis has also been examined by many researchers (Anson, 1982; Bjørklund, 1992; Christina et al., 1982; Klapp et al., 1974; Phillips \& Glencross, 1985), but these studies were also limited to upper extremity movements. For the above reasons, it can be said that the current study was relatively 
new and thus further research will be necessary to confirm the results and then apply them for practical use.

\section{Recommendations for Future Study}

An outcome of completing this study has led to several ideas for conducting future research. First, the number of participants in the current study was composed of only 12 male college aged individuals and the data from only 11 participants were deemed usable. Future studies might increase the number of participants to improve the power of the results. Moreover, participants in the current study performed one practice trial followed by 10 trials on each movement and across each mouth guard condition. These conditions were completely counterbalanced across participants. Although the primary researcher carefully checked the conditions which resulted from the reaction before the appearance of the stimulus or the failure of completing the movement, some of the collected data had to be excluded from processing and analysis. The exclusion of data was caused by a participant that moved his lower extremities or reacted with his preferred foot before the appearance of the stimulus light. These movements were noticed when observing the data of ground reaction force, and these movements made it impossible to detect the point when the reaction occurred. A 10 Newtons was set as the point where the initial movement of a trial occurred. Therefore, the collected data which did not exceed 10 Newtons from the baseline vertical ground reaction force on each trial were excluded from the process of analyzing data. The collected data which exceeded 10 Newtons from the baseline vertical ground reaction force were also screened for analyzing data if the collected data were out of the range of the SD1 (68\%) for each 
movement under each mouth guard condition. For these reasons future research should focus on the appropriate number of trials to reach a 10 criterion of 10 correct trials for all participants on each movement under each mouth guard condition.

A self-adapted mouth guard was used in the current study because it accounts for 90-95\% of the market share of all mouth guard users (Woodmansey, 1997). However, a custom-made mouth guard is more functional and is believed to be more durable and satisfactory than a self-adapted mouth guard (Ranalli, 2002: Newsome et al., 2001). To use a custom-made mouth guard in the current study setting for future study will provide additional information regarding the relationship between wearing a mouth guard and simple reaction time, and to compare the result from using a custom-made mouth guard with the results from using a self-adapted mouth guard in the current study settings might contribute a decision making which type of mouth guard is appropriate to wear for athletic population.

The entire EMG data from all participants were excluded from the current study. Anson (1982) succeeded to record the premotor and motor reaction times for the participants' right upper extremity. He asked his participants to set their tested forearm on the armrest of the chair. With this position, it is assumed that participants could relax their tested upper extremity on the armrest, and no muscle activities of the tested upper extremity affected the EMG data prior to stimulus. It might be difficult to maintain the standing position without activating lower extremity muscles; therefore an alternative testing position might help record the EMG data for the simple reaction times on the lower extremity by using a sitting position. The sitting position will help participants to 
relax their lower extremities, and prevent participants activating their lower extremities' muscles and make possible to record the premotor and motor reaction times on the lower extremities.

In the current study, a visual signal was used as a warning and a stimulus signs. The foreperiod interval was randomized between 1.135 and $1.243 \mathrm{~s}($ mean $=1.182, \mathrm{SD}=$ 0.152). Henry and Rogers (1960) in contrast, used a sound stimulus after a warning light with 1-4 s random foreperiod. There might be a different outcome between using visual and auditory stimuli with 1-4 s random foreperiod on reaction times.

Another suggestion for a future study as well as for gaining reliable results by comparing with the Henry and Rogers' study (1960) will be to use same study setting for an activating button (switch) of warning and stimulus signs. Henry and Rogers set an activating switch for sound warning sign at the out of participant's sight. Participants did not know when the sound warning sign would activate. In the current study, in contrast, the wireless computer mouse which activated the warning light on the screen of the laptop computer was set at next to the computer; therefore it was in view of participants. Participants might be able to prepare for the warning light even though the time (foreperiod) when the stimulus light would turn on was randomized by the program (National Instruments LabVIEW 7.0) in the laptop computer to prevent the participants anticipating the stimulus light.

\section{Summary}

In the current study, the null hypothesis that mouth guard condition would not affect simple reaction time of a whole body movement was accepted. However, there is a 
trend that the condition of wearing a self-adapted mouth guard resulted in shorter simple reaction time than the condition of not wearing a mouth guard only on the low and moderate complexity movements. Perhaps, this trend might result from reducing the electromechanical delay caused by stabilizing mandibular position while wearing a selfadapted mouth guard (Ishijima et al., 1998; Morozumi et al., 2004). In contrast, on the high complexity movement shorter simple reaction times were not found while wearing a self-adapted mouth guard than when not wearing a self-adapted mouth guard. A possible explanation for this phenomenon is that participants did not clench their teeth while performing the high complexity movement. While performing the high complexity movement, participants needed to coordinate stepping on three targets with their preferred foot in a specific order. The complicated movement might have distracted the participants from clenching their teeth.

The null hypothesis that movement complexity would not interact with mouth guard condition and the null hypothesis that movement complexity would not affect simple reaction time were rejected. This phenomenon can be explained by five characteristics of a movement which explained by increased number of body parts and the size of body parts exerted to perform a movement (Anson, 1982), duration of movement, accuracy of movement, directional change in movement, and distance of movement (Christina et al., 1982). Movement complexity has been found to affect simple reaction time; therefore simple reaction times in current study support previous research findings. 
The current study was relatively new study area which determined the relationship between use of a mouth guard and simple reaction time and between "memory drum" theory and movement complexity by examining lower extremity movements. Therefore, the further research will be required to confirm the results of the current study and to apply to the practical use. 


\section{References}

Anson, J. G. (1982). Memory drum theory: Alternative tests and explanations for the complexity effects on simple reaction time. Journal of Motor Behavior, 14(3), 228-246.

Badel, T., Jerolimov, V., \& Pandurić, J. (2007). Dental/orofacial trauma in contact sports and intraoral mouthguard programmes. Kinesiology, 39(1), 97-105.

Bjørklund, R. A. (1992). Effects of foreperiod and time on task on reaction time and movement time. Perceptual and Motor Skills, 74, 131-141. doi:10.2466/pms.1992.74.1.131

Bourdin, M., Brunet-Patru, I., Hager, P., Allard, Y., Hager, J., Lacour, J., \& Moyen, B. (2006). Influence of maxillary mouthguards on physiological parameters.

Medicine \& Science in Sports \& Exercise, 38(8), 1500-1504.

doi:10.1249/01.mss.0000228952.44850.eb

Burkett, L. N., \& Bernstein, A. (1983). The effect of mandibular position on strength, reaction time and movement time on a randomly selected population. New York State Dental Journal, 49(5), 281-285.

Christina, R. W., Fischman, M. G., Vercruyssen, M. P., \& Anson, J. G. (1982). Simple reaction time as a function of response complexity: Memory drum theory revisited. Journal of Motor Behavior, 14(4), 301-321.

Cornwell, H., Messer, L. B., \& Speed, H. (2003). Use of mouthguards by basketball players in Victoria, Australia. Dental Traumatology, 19, 193-203. doi:10.1034/j.1600-9657.2003.00202.x

Dillberović, N., Seifert, D., \& Jerolimov, V. (2004). The incidence of orofacial injuries in high-school basketball players. Kinesiology, 36(2), 233-238.

Eroglu, E., Diljin, K. A., \& Lutfi, B. M. (2006). Elite tae kwon do athletes' satisfaction with custom-made mouthguards. Dental Traumatology, 22, 193-197. doi:10.1111/j.1600-9657.2006.00385.x

Ferrari, C. M., \& Medeiros, J. M. F. (2002). Dental trauma and level of information: Mouthguard use in different contact sports. Dental Traumatology, 18, 144-147. doi:10.1034/j.1600-9657.2002.00017.x

Fischman, M. G., Christina, R. W., \& Anson, G. (2008). Memory drum theory's C movement: Revelations from Franklin Henry. Research Quarterly for Exercise and Sport, 79(3), 312-318. 
Fitts, P. M. (1954). The information capacity of the human motor system in controlling the amplitude of movement. Journal of Experimental Psychology, 47, 381-391.

Flores, M. T., Andersson, L., Andreasen, J. O., Bakland, L. K., Malmgren, B., Barnett, F., Bourguignon, C., DiAngelis, A., Hicks, L., Sigurdsson, A., Trope, M., Tsukiboshi, M., \& von Arx, T. (2007). Guidelines for the management of traumatic dental injuries. II. Avulsion of permanent teeth. Dental Traumatology, 23(3), 130-136. doi:10.1111/j.1600-9657.2007.00605.x

Going, R. E., Loehman, R. E., \& Chan, M. S. (1974). Mouthguard materials: Their physical and mechanical properties. The Journal of the American Dental Association, 89, 132-138.

Hawn, K. L., Visser, M. F., \& Sexton, P. J. (2002). Enforcement of mouthguard use and athlete compliance in national collegiate athletic association men's collegiate ice hockey competition. Journal of Athletic Training, 37(2), 204-208.

Henry, F. M. (1980). Use of simple reaction time in motor programming studies: A reply to Klapp, Wyatt, and Lingo. Journal of Motor Behavior, 12(2), 163-168.

Henry, F. M., \& Rogers, D. E. (1960). Increased response latency for complicated movements and a "memory drum" theory of neuromotor reaction. Research Quarterly, 31, 448-458.

Howell, M. L. (1953). Influence of emotional tension on speed of reaction and movement. The Research Quarterly, 24, 22-32.

Ishijima, T., Hirai, T., Koshino, H., Konishi, Y., \& Yokoyama, Y. (1998). The relationship between occlusal support and physical exercise ability. Journal of Oral Rehabilitation, 25, 468-471. doi:10.1046/j.1365-2842.1998.00254.x

Kecei, A. D., Cetin, C., Eroglu, E., \& Baydar, M. L. (2005). Do custom-made mouth guards have negative effects on aerobic performance capacity of athletes? Dental Traumatology, 21, 276-280. doi:10.1111/j.1600-9657.2005.00354.x

Kenyon, B. J., \& Loos, L. G. (2005) Comparing comfort and wearability between type III single-layered and double-layered EVA mouthguards. General Dentistry, 53(4), 261-264).

Klapp, S. T. (1980). The memory drum theory after twenty years: Comments on Henry's note. Journal of Motor Behavior, 12(2), 169-171.

Klapp, S. T., Wyatt, E. P., \& Lingo, W. M. (1974). Response programming in simple and choice reactions. Journal of Motor Behavior, 6(4), 263-271. 
Knapik, J. J., Marshall, S. W., Lee, R. B., Darakjy, S.s., Jones, S. B., Mitchener, T. A., delaCruz, G. G., \& Jones, B. H. (2007). Mouthguards in sport activities: History, physical properties and injury prevention effectiveness. Sports Medicine, 37(2), 117-144.

Knight, K. L. (2008). More precise classification of orthopaedic injury types and treatment will improve patient care. Journal of Athletic Training, 43(2), 117-118.

Kumamoto, D., \& Maeda, S. (2005). Are mouthguards necessary for basketball? Journal of the California Dental Association, 33(6), 463-470.

Labella, C. R., Smith, B.W., \& Sigurdsson, A. (2002). Effect of mouthguards on dental injuries and concussion in college basketball. Medicine \& Science in Sports \& Exercise, 34(1), 41-44.

Lieger, O., \& von Arx, T. (2006). Orofacial/cerebral injuries and the use of mouthguards by professional athletes in Switzerland. Dental Traumatology, 22, 1-6. doi:10.1111/j.1600-9657.2006.00328.x

Magill, R. A. (2006). Motor learning and control: Concepts and applications $\left(8^{\text {th }}\right.$. ed.). New York, NY: McGraw-Hill.

Morozumi, K., Yamamoto, I., Fujiwara, T., Nishiya, T., Takeuchi, Y., Umeki, C., \& Ichikawa, T. (2004). Effect of dentures wearing on motor reaction time and balance function in elderly people. Journal of Physiological Anthropology and Applied Human Science, 23, 129-137.

Newsome, P. RH., Tran, D. C., \& Cooke, M. S. (2001). The role of the mouthguard in the prevention of sports-related dental injuries: A review. International Journal of Pediatric Dentistry, 11, 396-404. doi:10.1046/j.0960-7439.2001.00304.x

Nowjack-Raymer, R. E., \& Gift, H. C. (1996). Use of mouthguards and headgear in organized sports by school-aged children. Public Health Reports, 111, 82-86.

Perunski, S., Lang, B., Pohl, Y., \& Filippi, A. (2005). Level of information concerning dental injuries and their prevention in Swiss basketball - A survey among players and coaches. Dental Traumatology, 21, 195-200.

Phillips, J., \& Glencross, D. (1985). The independence of reaction and movement time in programmed movements. Acta Psychologica, 59, 209-225. doi:10.1016/0001-6918(85)90045-9

Ranalli, D. N., (2002). Sports dentistry and dental traumatology. Dental Traumatology, 18, 231-236. doi:10.1034/j.1600-9657.2002.00122.x 
Santos, A. P. P., \& Monte Alto, L. A. (2006). Orofacial injury in a Brazilian professional basketball player: Case report. Dental Traumatology, 22, 169-171. doi:10.1111/j.1600-9657.2006.00344.x

Schmidt, R. A., \& Wrisberg, C. A. (2000). Motor learning and performance: A problembased learning approach $\left(2^{\text {nd }}\right.$. ed.). Champaign, Illinois: Human Kinetics.

Soporowski, N. J., Tesini, D. A., \& Weiss, A. I. (1994). Survey of orofacial sports-related injuries. Journal of the Massachusetts Dental Society, 43(4), 16-20.

Thomas, D. Q., Bowdoin, B. A., Brown, D. D., \& McCaw, S. T. (1998). Nasal strips and mouthpieces do not affect power output during anaerobic exercise. Research Quarterly for Exercise and Sport, 69(2), 201-204.

Tran, D., Cooke, M. S., \& Newsome, P. R. (2001). Laboratory evaluation of mouthguard material. Dental Traumatology, 17, 260-265. doi:10.1034/j.1600-9657.2001.170604.x

Vastardis, P. D. (2005). Athletic mouthguards: Indications, types, and benefits. Dentistry Today, 24(12), 52-55.

Woodmansey, K. F. (1997). Athletic mouth guards prevent orofacial injuries. Journal of American College Health, 45(4), 179-182. 
Appendix A

Questionnaire for Health History 


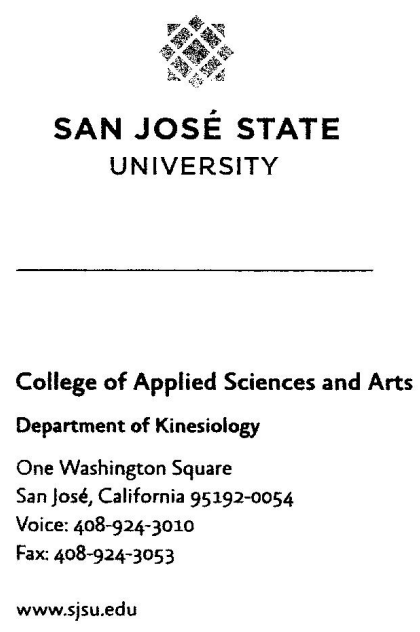

Name:

Questionnaire for Health History

Name:
Please surround your answer with a circle
Have you ever participated in organized scholastic athletics for at least
one year?
\[ \underline{\text { Yes }} \]

Have you ever worn a mouth guard while participating in physical activity?

$\underline{\text { Yes }} \quad / \quad \underline{\text { No }}$

Have you injured your toes

\begin{tabular}{|c|c|c|}
\hline within $0-4$ days & within $4-14$ days & more than 14 days \\
\hline \multicolumn{3}{|c|}{ arch of foot } \\
\hline within $0-4$ days & within $4-14$ days & more than 14 days \\
\hline \multicolumn{3}{|c|}{ heel of foot } \\
\hline within $0-4$ days & within $4-14$ days & more than 14 days \\
\hline \multicolumn{3}{|l|}{ ankle } \\
\hline within $0-4$ days & within $4-14$ days & more than 14 days \\
\hline \multicolumn{3}{|c|}{ Achilles tendon } \\
\hline within $0-4$ days & within $4-14$ days & more than 14 days \\
\hline \multicolumn{3}{|c|}{ gastrocnemius (cuff) muscle } \\
\hline within $0-4$ days & within $4-14$ days & more than 14 days \\
\hline
\end{tabular}


shin (front of lower leg)

within $0-4$ days $\quad$ within $4-14$ days more than 14 day
knee
within $0-4$ days within $4-14$ days more than 14 days
quadricep muscles
within $0-4$ days within $4-14$ days more than 14 days
hamstring muscles
within $0-4$ days $\quad \underline{\text { within } 4-14 \text { days }}$ more than 14 days
lower back
within $0-4$ days $\quad \underline{\text { within } 4-14 \text { days }}$ more than 14 days

Have you ever diagnosed by a doctor that you have a neuromuscular deficit?

$\underline{\text { Yes }} \quad / \quad \underline{\text { No }}$

Have you ever diagnosed by a doctor that you have a visual dysfunction?

Yes $\quad$ No

Have you ever diagnosed by a doctor that you have an auditory dysfunction?

Yes $\quad$ No


Appendix B

Permission for Redrawing of Howell Apparatus 


\section{Research Quarterly for Exercise and Sport}

Sponsored by the Research Consortium of the American Alliance for Health, Physical Education, Recreation and Dance, 1900 Association Drive, Reston, VA $20191-1598$

(703) 476-3400 (office) (703) 476-9527 (fax) • rqes@aahperd.org (e-mail)

September 6, 2011

Taijiro Hide

Department of Kinesiology

San Jose State University

San Jose, CA 95192-0054

Dear Mr. Hide,

Permission is granted to adapt one figure from Research Quarterly for Exercise and Sport (RQES; Vol. 79, pp. 312-318) in your master's thesis titled, Effects of Wearing a Mouth Guard and Movement Complexity on Simple Reaction Time. Please note the following:

- Permission includes non-exclusive world rights on a one-time only basis. Authors/publishers must request permission for each subsequent use of the material (i.e., future printings, editions, or for other media).

- Please use the following credit line with the material:

Reprinted with permission from Research Quarterly for Exercise and Sport, Vol. 79, No. 3, 312-318 (pages), Copyright (2008) by the American Alliance for Health, Physical Education, Recreation and Dance, 1900 Association Drive, Reston, VA 20191.

Thank you.

Sincerely,

Genda Inper

Linda Topper

Managing Editor, RQES 
Appendix C

Consent Form 
SAN JOSÉ STATE

UNIVERSITY

College of Applied Sciences and Arts

Department of Kinesiology

One Washington Square

San José, California 95192-0054

Voice: 408-924-3010

Fax: 408-924-3053

www.jssu.edu

\section{Consent form}

\section{Agreement to Participation in Research}

Taijiro Hide, a graduate student, would like to ask for your participation in a research study being conducted at San Jose State University. The title of the research is Effect of a Mouth Guard and Task Complexity on Simple Reaction Time.

The purpose of the research is to investigate if there is a difference in simple reaction time within two conditions (either not wearing a mouth guard or wearing a self-adapted mouth guard) on three simple movements of varying complexity.

In this research, you will be asked to perform a task that requires stepping quickly forward and back for a total of 66 trials (one practice trial at each condition on each movement and 10 trials for each condition which is without a mouth guard and with wearing a self-adapted mouth guard on each movement).

In addition to measuring simple reaction time, fractionated reaction time will be measured to analyze muscle activity while performing each task under each condition. Therefore, you will be asked to wipe off with alcohol pads, shave any hair with a disposable razor, rub with abrasive pads on your cheeks and insides of knee and cuff muscles on the both leg, and place the electrodes on these areas.

There is no compensation for your participation, and you will not receive direct benefits through this research, however you may gain an optimal idea for wearing a mouth guard while participating in specific physical activities such as basketball playing.

This research may contain a risk of the possibility of cutting skin by razor, and spraining an ankle or a knee. To minimize this risk, you will be given rests between trials.

Although the results of this research may be published, no information that could identify you will be included. To maintain confidentiality, each participant will be given an identifiable number, and only the participant and the researcher will know the number. Each participant's data will be kept under care of the researcher.

Page 1 of 2
Please initial here:
The Catifornia State University:
Chancellor's Office Bakersfield, Channel Islands, Chico, Dominguez Hitls, Los Angeles, Maritime Academy, Monterey Bay. Northridge, Pomana, Sacramento, San Bernardino, San Diego, San Francisco, San José, San Luis Obispo
San Marros, Sonoma, Stanislaus 
Any questions regarding to the study will be answered by Taijiro Hide, (509)991-2781 or taiji83@hotmail.com. Complaints about the research may be presented to Dr. Shirley Reekie, Chair of Kinesiology Department, at (408) 924-3010. If you have questions about your rights as a research participant or report a research-related injury, please contact Dr. Pamela Stacks, Associate Vice President for Graduate Studies and Research, at (408) 924-2427.

No service of any kind, to which you are otherwise entitled, will be lost or jeopardized if you choose not to participate in the study.

Your consent is being given voluntarily. You may refuse to participate in the entire or in any part of the study. If you decide to participate in the study, you are free to withdraw at any time without any negative effect on your relations with San Jose State University.

At the time that you sign this consent form, you will receive a copy of it for your records, signed and dated by the investigator.

- The signature of a subject on this document indicates agreement to participate in the study.

- The signature of a researcher on this document indicates agreement to include the above named subject in the research and attestation that the subject has been fully informed of his right.

Participant's Signature

Date

Investigator's Signature

Date

Page 2 of 2 


\section{Appendix D}

\section{Human Subjects-Institutional Review Board Approval}


SAN JOSÉ STATE UNIVERSITY

Division of Academic Affairs

Associate Vice President Graduate Studies \& Research

www.sjsu.edu/gradstudies

One Washington Square San José, California 95192-0025 Voice: $408-924-2427$

Fax: 408-924-2612

www.sjsu.edu

\section{To: Taijiro Hide}

From: Pamela Stacks, Ph.D.

Associate Vice President

Graduate Studies and Research

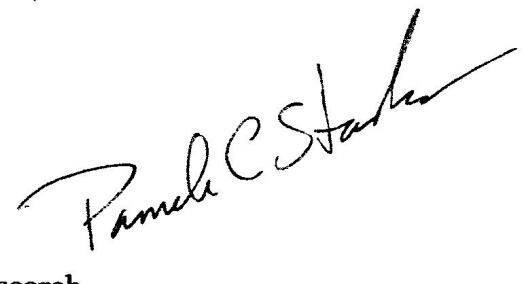

Date: July 6, 2010

The Human Subjects-Institutional Review Board has approved your request to use human subjects in the study entitled:

\section{"Effect of a Mouth Guard and Task Complexity on Simple Reaction Time"}

This approval is contingent upon the subjects participating in your research project being appropriately protected from risk. This includes the protection of the anonymity of the subjects' identity when they participate in your research project, and with regard to all data that may be collected from the subjects. The approval includes continued monitoring of your research by the Board to assure that the subjects are being adequately and properly protected from such risks. If at any time a subject becomes injured or complains of injury, you must notify Dr. Pamela Stacks, Ph.D. immediately. Injury includes but is not limited to bodily harm, psychological trauma, and release of potentially damaging personal information. This approval for the human subject's portion of your project is in effect for one year, and data collection beyond July 6, 2011 requires an extension request.

Please also be advised that all subjects need to be fully informed and aware that their participation in your research project is voluntary, and that he or she may withdraw from the project at any time. Further, a subject's participation, refusal to participate, or withdrawal will not affect any services that the subject is receiving or will receive at the institution in which the research is being conducted.

If you have any questions, please contact me at (408) 924-2427.

Protocol \#S1002199

cc: Emily Wughalter $\quad 0054$
The Califormia Stets University.

Bakersfield, Channel lslands, Chico, Dominguez Hills, Los Angeles, Maritime Academy, Monterey Bay, Northridge, Pomona, Sacramento, San Bernardino, San Diego, San Francisco, San Jose, San Luis Obispo,
San Marcos, Sonoma, Stanistaus 


\section{Appendix E}

Audio Instruction for the Order of the Independent Variable 
The taped instructions were played as a result of an order of independent variables. The independent variables which were mouth conditions and tasks was a within subject measure and counterbalanced across participant using a Lain Square design.

\section{Play audio instruction}

Thank you for participating in this study. This study will take place for the purpose of investigating the effects of whole body task with three varying complexities on simple reaction time (SRT) among Movement A which is a simple movement, Movement B, which is a moderate movement, and Movement C, which is a complex movement when not wearing a mouth guard and when wearing a self-adapted mouth guard. In this study, you will be asked to perform quick lower extremity movements. SRT will be measured and then fractionated by analyzing muscle activities while performing each task under each condition.

Before starting, I would like you to choose which foot (right or left) you prefer to use for Movement A, B, and C. Please tell me which foot you would like to use for the study.

\section{Stop audio instruction}

(Write the side of the foot which the participant chose)

\section{Start audio instruction}

You will perform Movement A while wearing a mouth guard first, Movement B while wearing a mouth guard second, Movement $\mathrm{C}$ while wearing a mouth guard third, Movement A without wearing a mouth guard fourth, Movement B without wearing a mouth guard fifth, and finally Movement $\mathrm{C}$ without wearing a mouth guard. 
You will have one practice trial to familiarize yourself with each movement before each test. For the test, you will perform 10 trials on each movement with each mouth condition. However, you may repeat the movement if you react before the appearance of the stimulus or fail to complete the movement. Between each trial, you will have 10 seconds to go back to the starting position and to be ready for the next trial. You will not receive any feedback about simple RT or movement through the tests.

Do you have any questions?

(Wait 10 seconds for questions and tape will be stopped if the participant has questions)

Next, the researcher will place the electrodes on your cheeks and on the inside of your knee and cuff muscles on both your legs. To place the electrodes on these areas, please wipe them down with alcohol pads, shave any hair with the shaver, and rub with abrasive pads on these areas. After you used the pads and razor, please discard them into the disposal container. Once you finished these preparations, the researcher will place the electrodes on those areas.

\section{Stop audio instruction}

(Wait until the electrodes will be placed on these areas)

\section{Start audio instruction}

Now you will perform Movement A while wearing a mouth guard. For this test, 
you will stand on a starting mat with your chosen foot while wearing a mouth guard. The stance of the feet will be set slightly wider than the distance of your shoulders. Then you will adopt an upright position with open hands (approximately $45^{\circ}$ shoulder abduction) and slightly bent knees (approximately $45^{\circ}$ knee flexion). A warning light will be given before the stimulus light. From this posture, you will remove as quickly as possible your chosen foot, which is on the starting mat, in response to the stimulus light. The time interval from the appearance of the stimulus light to the initiation of removing the chosen foot from the starting mat as well as the fractionated RTs from each electrode will be recorded.

Now the researcher will demonstrate the movement.

\section{Stop audio instruction}

The primary researcher will demonstrate Movement A.

\section{Play audio instruction}

Do you have any questions?

(Wait 10 seconds for questions and tape will be stopped if the participant has questions)

Now you will have a practice trial for Movement A to familiarize yourself with the movement. Please stand on the mat and perform Movement A. 


\section{Stop audio instruction}

(Wait till the participant complete the movement)

\section{Start audio instruction}

Now you will begin to perform Movement A while wearing a mouth guard. Please wear the mouth guard and stand on the starting mat with your chosen foot. Once you stand on the mat, the test will begin.

\section{Stop audio instruction}

The testing Movement A with wearing the mouth guard will continue until the primary researcher gain complete 10 simple RTs.

\section{Start audio instruction}

Now you will perform Movement B while wearing a mouth guard. For this test, you will stand on the starting mat with your chosen foot while wearing a mouth guard. You will adopt the same stance and posture as the previous test. A warning light will be given before the stimulus light. From this posture, you will remove as quickly as possible your chosen foot, which is on the starting mat, in response to the stimulus light and to move the foot forward to step on Mat A. The time interval from the appearance of the stimulus light to the initiation of removing the chosen foot from the starting mat as well as the fractionated RTs from each electrode will be recorded.

Now the researcher will demonstrate the movement. 


\section{Stop audio instruction}

The primary researcher will demonstrate Movement $B$.

\section{Play audio instruction}

Do you have any questions?

(Wait 10 seconds for questions and tape will be stopped if the participant has questions)

Now you will have a practice trial for Movement B to familiarize yourself with the movement. Please stand on the mat and perform Movement B.

\section{Stop audio instruction}

(Wait till the participant complete the movement)

\section{Start audio instruction}

Now you will begin to perform Movement B while wearing a mouth guard. Please wear the mouth guard and stand on the starting mat with your chosen foot. Once you stand on the mat, the test will begin.

\section{Stop audio instruction}

The testing Movement B with wearing the mouth guard will continue until the primary researcher gain complete 10 simple $R T S$ 


\section{Start audio instruction}

Now you will perform Movement $\mathrm{C}$ while wearing a mouth guard. For this test, you will stand on the starting mat with your chosen foot while wearing a mouth guard. You will adopt the same stance and posture as the previous tests. A warning light will be given before the stimulus light. From this posture, you will remove your chosen foot, which is on the starting mat, in response to the stimulus light, to move the foot diagonally forward to step on Mat B, to move the foot backward to step on Mat C, and to move the foot diagonally forward to step on Mat A. You need to complete the series of movements as quickly as possible. The time interval from the appearance of the stimulus light to the initiation of removing the chosen foot from the starting mat as well as the fractionated RTs from each electrode will be recorded.

Now the researcher will demonstrate the movement.

\section{Stop audio instruction}

The primary researcher will demonstrate Movement $C$.

\section{Play audio instruction}

Do you have any questions?

(Wait 10 seconds for questions and tape will be stopped if the participant has questions) 
Now you will have a practice trial for Movement $\mathrm{C}$ to familiarize yourself with the movement. Please stand on the mat and perform Movement C.

\section{Stop audio instruction}

(Wait till the participant complete the movement)

\section{Start audio instruction}

Now you will begin to perform Movement $\mathrm{C}$ while wearing a mouth guard. Please wear the mouth guard and stand on the starting mat with your chosen foot. Once you stand on the mat, the test will begin.

\section{Stop audio instruction}

The testing Movement $C$ with wearing the mouth guard will continue until the primary researcher gain complete 10 simple $R T S$

\section{Start audio instruction}

Now you will perform Movement A without wearing a mouth guard. For this test, you will stand on the starting mat with your chosen foot without wearing a mouth guard. You will adopt the same stance and posture as the previous tests. A warning light will be given before the stimulus light. From this posture, you will remove as quickly as possible your chosen foot, which is on the starting mat, in response to the stimulus light. The time interval from the appearance of the stimulus light to the initiation of removing the chosen 
foot from the starting mat as well as the fractionated RTs from each electrode will be recorded.

Now the researcher will demonstrate the movement.

\section{Stop audio instruction}

The primary researcher will demonstrate Movement A.

\section{Play audio instruction}

Do you have any questions?

(Wait 10 seconds for questions and tape will be stopped if the participant has questions)

Now you will have a practice trial for Movement A to familiarize yourself with the movement. Please stand on the mat and perform Movement A.

\section{Stop audio instruction}

(Wait till the participant complete the movement)

\section{Start audio instruction}

Now you will begin to perform Movement A without wearing a mouth guard. Please stand on the starting mat with your chosen foot. Once you stand on the mat, the test will begin. 


\section{Stop audio instruction}

The testing Movement A without wearing a mouth guard will continue until the primary researcher gain complete 10 simple RTs.

\section{Start audio instruction}

Now you will perform Movement B without wearing a mouth guard. For this test, you will stand on the starting mat with your chosen foot without wearing a mouth guard. You will adopt the same stance and posture as the previous tests. A warning light will be given before the stimulus light. From this posture, you will remove your chosen foot, which is on the starting mat, in response to the stimulus light and to move as quickly as possible the foot forward to step on Mat A. The time interval from the appearance of the stimulus light to the initiation of removing the chosen foot from the starting mat as well as the fractionated RTs from each electrode will be recorded.

Now the researcher will demonstrate the movement.

\section{Stop audio instruction}

The primary researcher will demonstrate Movement $B$.

\section{Play audio instruction}

Do you have any questions?

(Wait 10 seconds for questions and tape will be stopped if the participant has questions) 
Now you will have a practice trial for Movement B to familiarize yourself with the movement. Please stand on the mat and perform Movement B.

\section{Stop audio instruction}

(Wait till the participant complete the movement)

\section{Start audio instruction}

Now you will begin to perform Movement B without wearing a mouth guard. Please stand on the starting mat with your chosen foot. Once you stand on the mat, the test will begin.

\section{Stop audio instruction}

The testing Movement B without wearing a mouth guard will continue until the primary researcher gain complete 10 simple $R T S$

\section{Start audio instruction}

Now you will perform Movement $\mathrm{C}$ without wearing a mouth guard. For this test, you will stand on the starting mat with your chosen foot without wearing a mouth guard. You will adopt the same stance and posture as the previous tests. A warning light will be given before the stimulus light. From this posture, you will remove your chosen foot, which is on the starting mat, in response to the stimulus light, to move the foot diagonally forward to step on Mat B, to step the foot backward to Mat C, and to move the foot diagonally forward to step on Mat A. You need to complete the series of movements as quickly as possible. The time interval from the appearance of the stimulus light to the 
initiation of removing the chosen foot from the starting mat as well as the fractionated RTs from each electrode will be recorded.

Now the researcher will demonstrate the movement.

\section{Stop audio instruction}

The primary researcher will demonstrate Movement $C$.

\section{Play audio instruction}

Do you have any questions?

(Wait 10 seconds for questions and tape will be stopped if the participant has questions)

Now you will have a practice trial for Movement $\mathrm{C}$ to familiarize yourself with the movement. Please stand on the mat and perform Movement C.

\section{Stop audio instruction}

(Wait till the participant complete the movement)

\section{Start audio instruction}

Now you will begin to perform Movement $\mathrm{C}$ without wearing a mouth guard. Please stand on the starting mat with your chosen foot. Once you stand on the mat, the test will begin. 


\section{Stop audio instruction}

The testing Movement $C$ without wearing a mouth guard will continue until the primary researcher gain complete 10 simple RTs

\section{Start audio instruction}

You have now completed the testing for assessing the difference in simple RT among three different types of movement under two mouth conditions. You can keep the mouth guard for protecting your mouth while playing sports. Thank you very much for your participation and your time. 